\title{
Feedback mechanisms at inorganic-polyelectrolyte interfaces for applied materials
}

1 Nikolay V. Ryzhkov PhD student, ITMO University, St Petersburg, Russian Federation

2 Nadzeya Brezhneva PhD student, Chemistry Department, Belarusian State University, Belarus
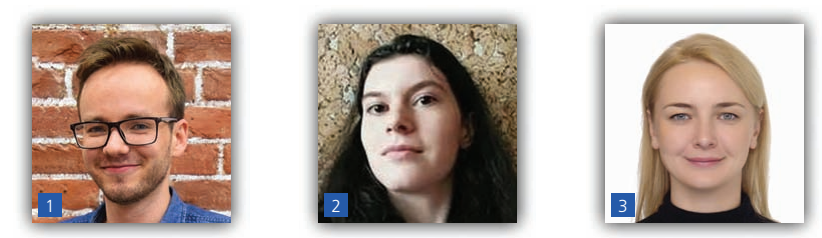

3 Ekaterina V. Skorb

Professor, ITMO University, St Petersburg, Russian Federation (corresponding author: skorb@corp.ifmo.ru)

Non-linear processes at the interface between inorganic and polymeric species mimic a wide variety of natural processes such as stimulus-responsive behavior, self-healing, actuation, transport and delivery, and $\mathrm{pH}$ buffering. There are plenty of models describing phenomena at solid-polymer and polymer-liquid interfaces, but they do not provide complete understanding of the occurring processes. The authors analyze here recent progress in fundamental aspects of programmable materials based on polyelectrolyte feedback mechanisms on inorganic surfaces of applied materials in (a) photochemistry (focus on semiconductor-polyelectrolyte interfaces), (b) electrochemistry and (c) self-adaptive materials. The functionalization of the inorganic surface with polyelectrolyte layers provides an opportunity to construct novel hybrid materials with improved characteristics in comparison with pristine inorganic analogues. The importance of the transition from traditional to system thinking is highlighted, as well as the hierarchical scale of the time of polyelectrolyte responses due to complex overlapping between the processes of ion diffusion, chain site diffusion and self-diffusion.

\section{Introduction}

One of today's research interests focuses on the study of naturemimicking interfaces of solid components and polymers (e.g. semiconductor-metal, ${ }^{1}$ semiconductor-insulator, ${ }^{2}$ semiconductorpolymer $^{3}$ and metal-polymer ${ }^{4}$ ). However, understanding the fundamental basis of the processes occurring on these interfaces is still a challenge, which substantially limits fabrication of novel high-performance devices and the improvement of already existing ones. ${ }^{5}$ Such hybrid structures can be regarded as complex interfaces, and, under an external stimulus (e.g. electromagnetic irradiation and electric field) of an appropriate intensity, nonlinear phenomena can take place in the system. ${ }^{6,7}$ Particularly, ultraviolet (UV) or visible range irradiation can lead to the nonlinear response of the semiconductor, leading to the appearance of the functions of intensity modulation, ${ }^{8}$ harmonic generation, ${ }^{9}$ spatial and temporal pulse shaping ${ }^{10}$ and so on, providing opportunities for optical processing of information. ${ }^{11}$ The non-linear phenomena at the semiconductor-polymer interface determine the non-linear optical properties of the hybrids ${ }^{11}$ and the non-linear charge transfer at the inorganic-organic interface. ${ }^{1,12}$ Also, an interesting stimulus-coupling phenomenon can take place on the semiconductor-soft matter interface.
Applying an external electromagnetic field can lead to the transformation of the initial energy of photons into a gradient of ions (particularly protons ${ }^{13}$ ), which can directly activate the $\mathrm{pH}$-sensitive polymer component. Polyelectrolytes (particularly weak polyelectrolytes) are known to exhibit pH-tunable properties. $^{14}$ In fact, such hybrid systems exhibit several responses: (a) photocatalytic reactions on the irradiated semiconductor surface and the consequent acidification, (b) changes in the parameters of the polymeric $\mathrm{pH}$-sensitive layer and (c) self-adaptive regulation (Figure 1).

In this paper, the authors focus on the analysis of stimulusresponsive solid-polyelectrolyte multilayer (PEM) interfaces with the further potential application of such structures in the design of smart materials. The photocatalytic activity of hybrids and the effect of the introduction of polyelectrolytes on the overall performance of the composite structure are discussed in Section 2.1. The electrochemical performance of multilayer-coated electrodes and their possible applications as well as the analysis of semiconductor-polyelectrolyte interfaces for photoelectrochemical applications are described in Section 2.2. Section 2.3 is devoted to the importance of self-adaptive systems. 


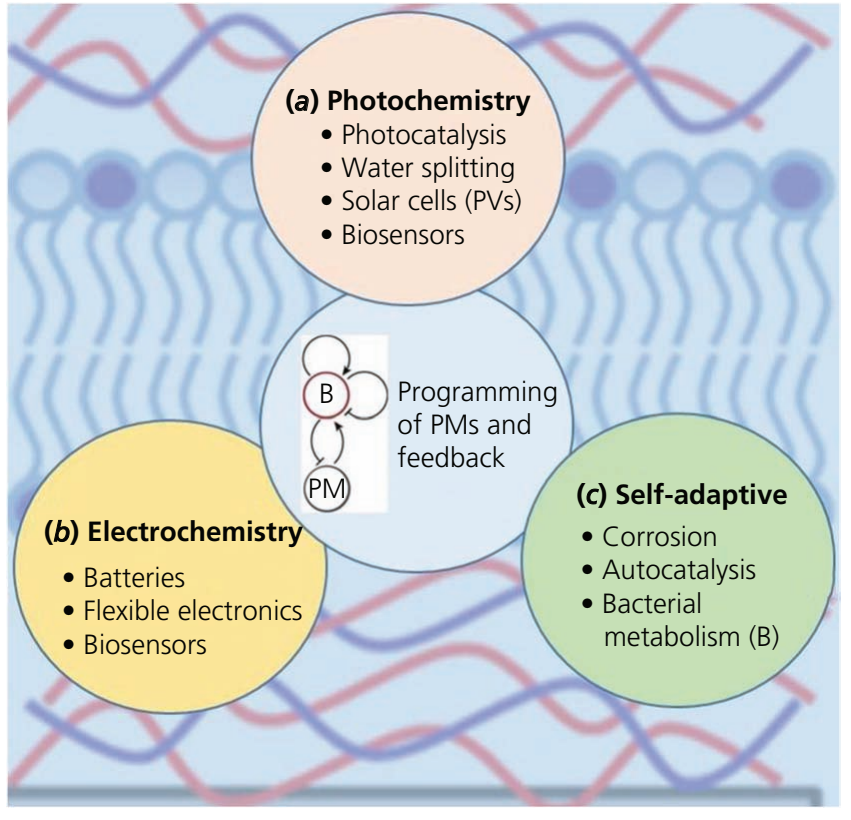

Figure 1. Formation of a PM with feedback (so-called intelligent, smart or stimulus-responsive materials), highlighting external stimuli: (a) photoactivation, (b) electrochemical switching and (c) most advanced PMs designed as self-adaptive materials. The chosen applied areas for PMs are also highlighted. The inset in the center shows the possibility of using PMs for bacterial colonies' (B) activation or inhibition with simultaneous active change of PMs due to bacterial metabolism. The background highlights solid-polyelectrolyte interfaces and in some cases LB interfaces, which are important in the architecture of PMs with a submicron precision

\section{Discussion}

\subsection{Basics of regulation of photocatalytic properties at} interfaces

\subsubsection{Photon-to-proton conversion at the semiconductor-polyelectrolyte interface}

Hybrid systems based on semiconductors and polyelectrolytes could be divided into several categories (Table 1) - for example, hollow micro- and nano-objects (microcapsules, ${ }^{17,18,20,24,26-28}$ nanofibers ${ }^{16}$ ), layer-by-layer (LbL) films, ${ }^{19,21}$ self-assembled thin films, ${ }^{22,23,30}$ surface-imprinted materials ${ }^{31}$ or cross-linked composite materials. ${ }^{25}$ Such systems are important for various applications (Figure 1) - for example, photocatalysis, water splitting, solar cells (photovoltaics (PVs)) and biosensors. Polyelectrolytes can be often exploited as a freestanding matrix for embedding semiconductor nanoparticles into their structure ${ }^{25,28,29,32-34}$ or act as monolayers in LbL-assembled multilayers or self-assembled coatings along with semiconductor films. ${ }^{16,19,21,35}$ Such hybrid systems possess, on the one hand, the properties of semiconductor materials photocatalytic activity, chemical stability, absorbance in the UV range (for titanium dioxide $\left(\mathrm{TiO}_{2}\right)$ and zinc oxide $(\mathrm{ZnO})$ ) or visible range (cadmium sulfide (CdS) and cadmium selenide (CdSe)) and, on the other hand, the properties of the organic compartment softness and flexibility.
Systems based on polyelectrolytes and semiconductors often exhibit synergistic effects - for example, enhancement of the semiconductor photocatalytic activity for environmental remediation applications (decomposition of dye or organic pollutants), ${ }^{16-20,24,26-28}$ and increase in the biocidal activity of the hybrid antimicrobial materials. $^{21}$ Figure 2(a) demonstrates the materials under consideration and their feedback changes that determine a wide range of applications. The importance of the transition from traditional to system thinking ('dynamic thinking') (Figure 2(b)) is highlighted as well as the hierarchical scale of the time of polyelectrolyte responses due to complex overlapping between the processes of ion diffusion, chain site diffusion and self-diffusion. Introducing the term 'dynamic thinking' with regard to materials, the authors would like to emphasize the complexity of processes occurring in heterostructured solid-polyelectrolyte stimulus-responsive programmable materials (PMs) with synergetic effects of output and complex networks of feedback with non-linear time-dependent development.

Fares and Schlenoff, ${ }^{36}$ Fares et al.,${ }^{37}$ Schlenoff ${ }^{38}$ and Delgado and Schlenoff ${ }^{39}$ in their studies discussed the diffusion processes in polyelectrolyte complexes and PEMs of certain architecture, taking into account small ion diffusion, site diffusion and polymer diffusion (Figure 2(c)). Both components - semiconductor and polyelectrolytes - affect each other. The topic under consideration includes the influence of photogenerated charges near the irradiated semiconductor surface on the properties of soft matter and the impact of soft matter on the photostimulated properties of the semiconductor. Photon absorption, generation of charge carriers under irradiation, chemical conversion into $\mathrm{pH}$ gradient, lifetimes and LbL stability are the general features considered in the characterization of semiconductor-polyelectrolyte systems. Titanium dioxide is not a specific semiconductor with the possibility of converting incident photons into a gradient of photogenerated species (particularly protons - light- $\mathrm{pH}$ coupling); however, this surface effect was studied in detail on titania. ${ }^{19}$ Thus, titanium dioxide can be regarded as the first candidate for creating a predictive theory of light-pH coupling for advanced materials with a stimulus-responsive behavior. In the following, it will be possible to expand the discussion to other semiconductors - for example, silicon, ${ }^{40} \mathrm{~A}^{\mathrm{III}} \mathrm{B}^{\mathrm{V} 5}$ and even perovskites. ${ }^{41}$

Surface $\mathrm{pH}$ change was studied in situ with the scanning ion-selective electrode technique (SIET) (Figure 3). ${ }^{42}$ For $\mathrm{pH}$ modulation with light, it is important to understand how photoinitiated processes on titanium dioxide result in the transformation of light into a $\mathrm{pH}$ change, including localization of the effect. SIET was applied to map the activity and migration of hydrogen $\left(\mathrm{H}^{+}\right)$ions over the titanium dioxide surface. SIET is a unique technique available for measuring in situ changes in ion concentrations locally in space and time. The main advantage of this unique method is that it allows performing measurements of local $\mathrm{pH}$ changes near the surface without any $\mathrm{pH}$-sensitive markers, which may potentially affect the photoreactions in the system. Maps of the $\mathrm{pH}$ were collected for pristine titanium dioxide before illumination (Figure 3(a)), during illumination 
Table 1. Selected examples of semiconductor-polyelectrolyte applied systems

\begin{tabular}{|c|c|c|c|c|}
\hline \multicolumn{3}{|c|}{ Semiconductor-polyelectrolyte hybrid system } & \multirow{2}{*}{$\begin{array}{l}\text { Possible applications of the hybrid } \\
\text { system }\end{array}$} & \multirow{2}{*}{ References } \\
\hline Semiconductor & Polyelectrolytes & Type of the system & & \\
\hline $\begin{array}{l}\text { Titanium dioxide } \\
\left(\mathrm{TiO}_{2}\right)\end{array}$ & PAH, PSS & $\begin{array}{l}\text { Hollow microcapsules - walls } \\
\text { of PEMs with incorporated } \\
\text { titania }\end{array}$ & $\begin{array}{l}\text { Photocatalytic microreactors for } \\
\text { microheterogeneous photoreduction } \\
\text { of metal ions from aqueous } \\
\text { solutions, }{ }^{10,11,15} \text { drug delivery } \\
\text { systems, cosmetics and } \\
\text { environmental engineering }{ }^{14}\end{array}$ & $\begin{array}{l}\text { Walker et al., }{ }^{10} \\
\text { Ropp et al., }{ }^{11} \\
\text { Lonergan, }{ }^{12} \\
\text { Skorb et al., } \\
\text { Mamidala } \\
\text { et al. }{ }^{15}\end{array}$ \\
\hline Titanium dioxide & Chitosan & $\begin{array}{l}\text { Surface-imprinted core-shell } \\
\text { composite materials }\end{array}$ & $\begin{array}{l}\text { Degradation of environmental organic } \\
\text { pollutants }\end{array}$ & Pan et al. ${ }^{16}$ \\
\hline Titanium dioxide & PAH, PSS & $\begin{array}{l}\text { Hybrid multilayered hollow } \\
\text { nanofibers }\end{array}$ & & $\begin{array}{l}\text { Shchukin and } \\
\text { Sviridov }^{17}\end{array}$ \\
\hline Titanium dioxide & PEI, PSS & $\begin{array}{l}\text { Sprayed LbL assembly of } \\
\text { titanium dioxide } \\
\text { photocatalyst with } \\
\text { polyelectrolytes for } \\
\text { polyester textile } \\
\text { functionalization }\end{array}$ & Antimicrobial textiles & Shchukin et al. ${ }^{18}$ \\
\hline $\begin{array}{l}\text { Cadmium sulfide } \\
\text { (CdS), titanium } \\
\text { dioxide }\end{array}$ & Chitosan & Cross-linked composite films & $\begin{array}{l}\text { Decolorization treatment of dye- } \\
\text { containing effluents }\end{array}$ & Sun et al. ${ }^{19}$ \\
\hline Titanium dioxide & PAH, PSS & $\begin{array}{l}\text { LbL-fabricated multilayer } \\
\text { coating on wood surface }\end{array}$ & $\begin{array}{l}\text { Multifunctional coatings for wood } \\
\text { surface protection }\end{array}$ & $\begin{array}{l}\text { Shchukin and } \\
\text { Sukhorukov }\end{array}$ \\
\hline Titanium dioxide & $\begin{array}{l}\text { Chitosan-grafted-poly }(N \text { - } \\
\text { methylaniline) }\end{array}$ & $\begin{array}{l}\text { Nanografted polymeric } \\
\text { composites }\end{array}$ & Environmental remediation & Carre et al. ${ }^{21}$ \\
\hline Titanium dioxide & Chitosan & Sorbent beads & Wastewater treatment & Dal'Acqua et al. ${ }^{22}$ \\
\hline Cadmium sulfide & PDDA & Spherical nanosized particles & $\begin{array}{l}\text { Photocatalytic removal of organic } \\
\text { pollutants }\end{array}$ & Faria et al. ${ }^{23}$ \\
\hline Titanium dioxide & $\begin{array}{l}\text { Poly(methacrylic } \\
\text { acid-ethylene glycol } \\
\text { dimethacrylate-3- } \\
\text { (trimethoxysilyl) } \\
\text { propylmethacrylate }\end{array}$ & $\begin{array}{l}\text { Hollow composite } \\
\text { microcapsules }\end{array}$ & Wastewater treatment & Shchukin et al. ${ }^{24}$ \\
\hline Titanium dioxide & PEI & $\begin{array}{l}\text { Hybrid nanocomposites with } \\
\text { multiwalled carbon } \\
\text { nanotubes }\end{array}$ & Artificial photosynthetic systems & Zhu et al. ${ }^{25}$ \\
\hline $\begin{array}{l}\text { Titanium dioxide, } \\
\text { cadmium selenide } \\
\text { (CdSe) }\end{array}$ & PAH, PAA, PEDOT:PSS & Self-assembled thin films & Hydrogen-producing devices & Timin et al. ${ }^{26}$ \\
\hline Titanium dioxide & PAH, PAA & Self-assembled thin films & Photocatalytic thin films & $\begin{array}{l}\text { Gao et al.., }{ }^{27} \text { Bang } \\
\text { et al. }{ }^{28}\end{array}$ \\
\hline Titanium dioxide & PEI & $\begin{array}{l}\text { Colloidal particles embedded } \\
\text { in a polyethylene matrix }\end{array}$ & & Essawy et al. ${ }^{29}$ \\
\hline
\end{tabular}

(Figure 3(b)), $20 \mathrm{~min}$ after switching the illumination off and during $40 \mathrm{~min}$ of relaxation (Figure 3(c)). The proton distribution maps show that protons were generated under irradiation. Thus, it is possible to couple light and $\mathrm{pH}$, and the authors know how to perform characterization of the system in situ and visualize chemical processes under local illumination.

\subsubsection{Nanometer-thick polyelectrolyte layer regulates semiconductor functional properties}

It is worth mentioning that $\mathrm{LbL}$ assembly allows the formation of an efficient structure for fast trapping of chemical species - for example, hydrogen ions (Table 1, Figure 4). The kinetics of light-pH-coupled actuation and modulation of LbL films and the study of the relaxation processes are in focus for the design of applied materials and PMs.
An increase in the photocatalytic activity in hybrid systems (e.g. poly (ethyleneimine) (PEI)-grafted multiwalled nanotubes in combination with titanium dioxide particles), particularly the enhancement of the titanium dioxide photoactivity in the UV range, can be explained by the auxochrome effect caused by the presence of $-\mathrm{NH}_{2}$ groups in the polyelectrolyte. $^{48}$ The high self-decontaminating activity of PEI-titanium dioxide-based antimicrobial textiles was explained as due to the combination of the biocidal photocatalytic activity of titanium dioxide and biocidal activity of PEI. ${ }^{21}$

Vallejo-Montesinos et $a l .{ }^{49}$ reported a decrease in the photocatalytic activity of titanium dioxide-PEI particles embedded into a polyethylene matrix in comparison with that of a control sample containing pure titanium dioxide. The authors explain this passivation of photoactivity as due to the chemical affinity of the polyelectrolyte 


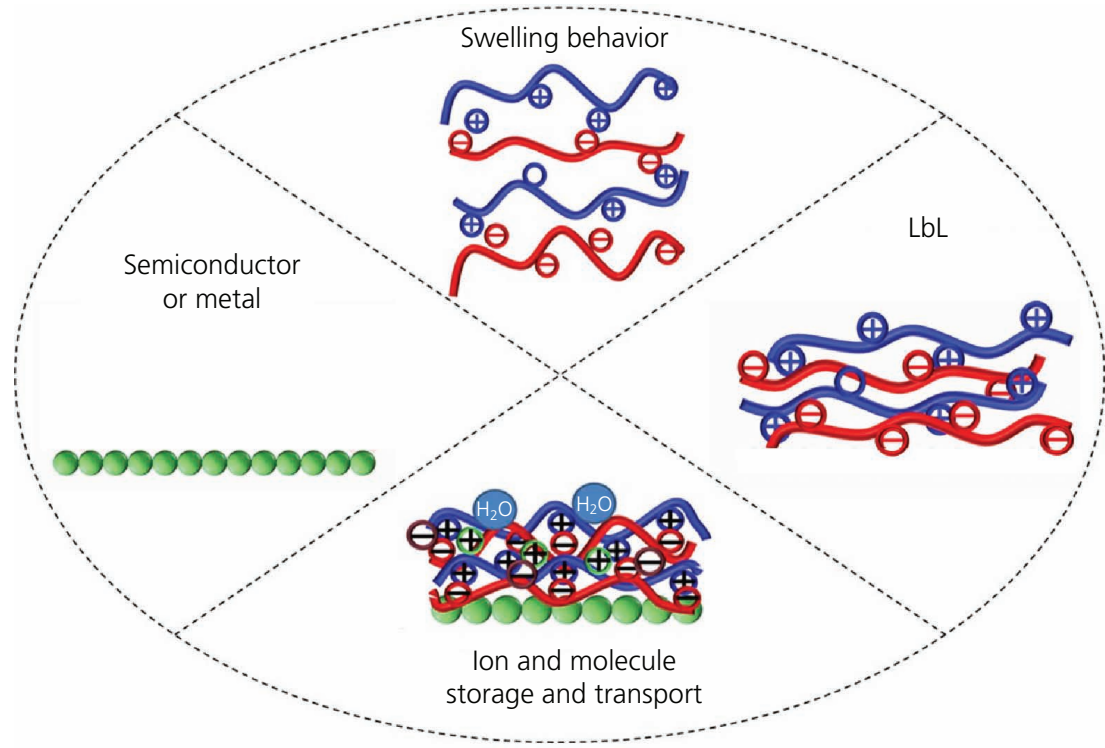

(a)

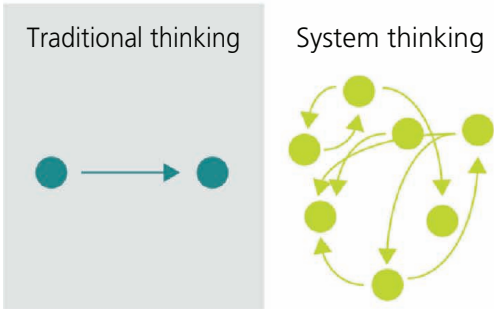

(b)

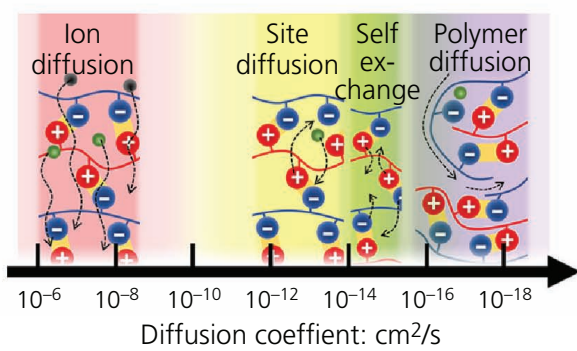

(c)

Figure 2. Schematic depiction of PM components and their dynamic thinking. (a) The solid (semiconductor or metal)-polyelectrolyte interface is in focus for its nanostructuring for a programmable swelling behavior, ion and molecule storage and transport against environmental changes and response to stimuli. (b) It is important in PM to transfer from traditional thinking to complex thinking. (c) Various time lines for diffusion coefficients in polyelectrolyte assembly that are important in predicting the PM response. Adapted from Fares and Schlenoff ${ }^{36}$

to the polymeric matrix and prevention of the floating of titanium dioxide particles to the surface of the composite during the preparation using an extrusion technique. The particles remained in the bulk of the composite due to the good integration of PEI-coated particles into the polymeric matrix, and these could not reach the surface so as to be irradiated and produce the photocatalytic activity.

Demonstrated recently in the authors' work ${ }^{43,44}$ was the alteration in the titanium dioxide-polyelectrolyte hybrid photoactivity by variation of the chitosan or PEI buffer layer position in an LbL assembly. The combination of the external stimulus (in the authors' case, UV irradiation) and the consequent $\mathrm{pH}$ gradient formation near the irradiated surface of the semiconductor ${ }^{42}$ can be regarded as stimulus-coupling activation of the semiconductor-polyelectrolyte hybrid system. Chitosan and PEI are known to exhibit 'proton sponge' properties by the trapping of hydrogen ions with $\mathrm{NH}_{2}$ groups. Under UV irradiation of the hybrids, the 'photon-to-proton conversion' (i.e. the transformation of electromagnetic irradiation energy into proton flux on the irradiated surface of titanium dioxide through a series of reduction/oxidation (red/ox) reactions with water) takes place. Recent work efficiently used the approach to control surface properties of titania.

Recently, the protection function against supramolecular disassembly of chitosan deposited on the surface of titanium dioxide has been demonstrated (Figures 4(a) and 4(b)). ${ }^{43}$ The combination of triaminopyrimidine and cyanuric acid modified with a hexanoic acid side chain is known to be assembled-disassembled reversely with $\mathrm{pH}$ change in the surrounding media. In the authors' work, it was shown that the assembly deposited onto the titanium dioxide-chitosan surface after irradiation remained on the surface without being destroyed and disassembled. This led to the confirmation of the hypothesis exploiting chitosan as a buffering protective layer for trapping photogenerated hydrogen ions.

The generation of protons leads to a decrease in the subsurface $\mathrm{pH}$ value. Titanium dioxide is known to exhibit higher 


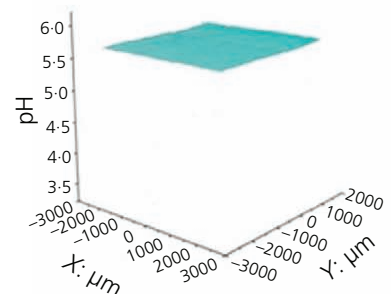

(a)

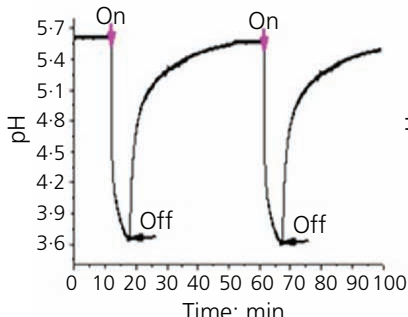

(d)

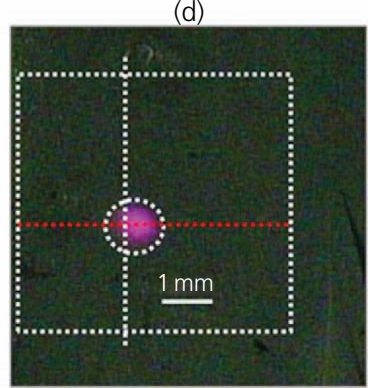

(g)

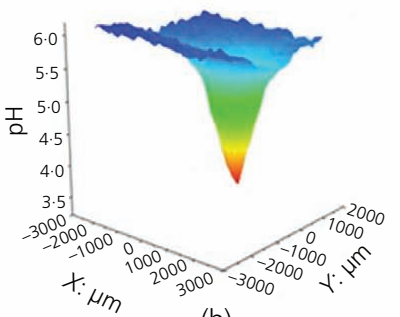

(b)

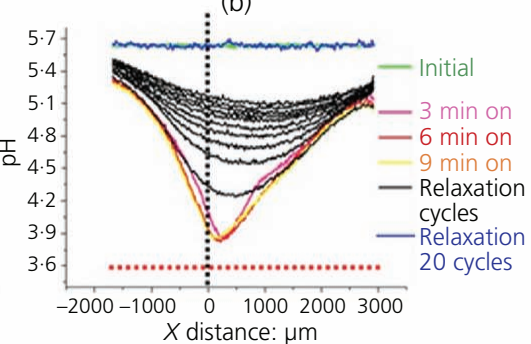

(e)

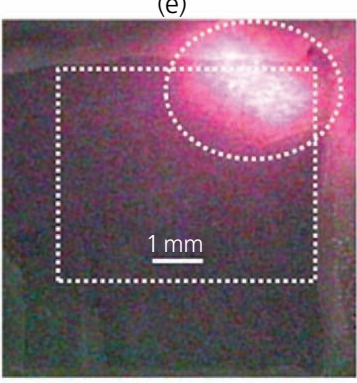

(h)

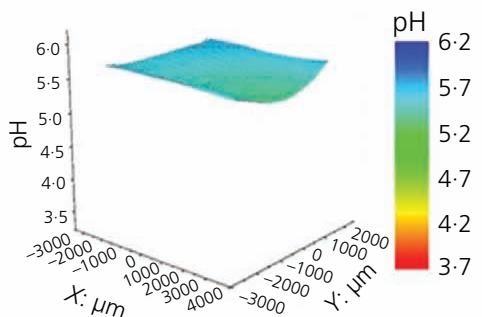

(c)

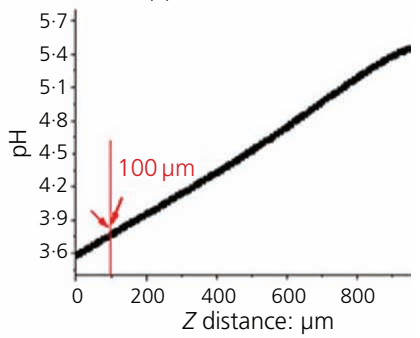

(f)

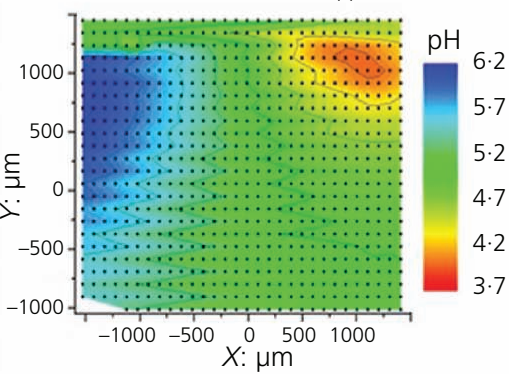

(i)

Figure 3. Light-pH coupling on a semiconductor surface. Maps obtained by the in situ SIET to analyze local pH gradients generated on nanostructured titanium dioxide: (a) before irradiation; (b) during local irradiation; (c) after irradiation (20 min of relaxation). (d) pH measurement inside an irradiation spot (shown in panel (g)) and single-spot time-evolution measurements on a titania layer after switching on and switching off the light. (e) Local pH measurements in a line (shown in panel $(\mathrm{g}$ ) in (red)) before, during and after irradiation (the maximum coincides with the position of the irradiation spot; the time of measurement of each line was $3 \mathrm{~min}$ ). ( $\mathrm{f}$ ) $\mathrm{pH}$ in the $Z$ direction during illumination inside the irradiated spot. (g) $X-Y$ dashed lines shown in the optical image of the surface and the location of the focused irradiation spot on titanium dioxide described earlier (panels (a)-(e)) and mapped in panels (a)-(c). (h) $X-Y$ optical image with defocused light to show the flexibility of the method to change the intensity of illumination and its location and effect on the $\mathrm{pH}$ gradient of the surface with corresponding (i) $\mathrm{pH}$ map with color-pointed $\mathrm{pH}$ areas. Reprinted from Maltanava et al. ${ }^{42}$

photoactivity in the acidic medium, but, in the case of immediate binding of photogenerated protons by the PEI layer, the photoactivity can decrease. The authors showed that the titanium dioxide-poly(styrene sulfonate) (PSS)-PEI photocatalytic activity is around two times lower in comparison with that of titanium dioxide-PEI and around four times lower than in the case of pure titanium dioxide (Figures 4(c) and 4(d)). In the photoelectrochemical experiments, the authors also noticed a decrease in the photocurrent values. The authors assume that such decrease in the photoactivity can be related to the variation in buffering properties of PEI either deposited directly on the titanium dioxide surface or separated by a nanoscale-thick $(\sim 5 \mathrm{~nm})$ PSS layer. Another demonstration of the mild photocatalytic activity of the titanium dioxide-PSS-PEI hybrid was described by Brezhneva et $a l .{ }^{44}$ Changes in the titania surface state can be efficiently controlled by impedance study (Figures 4(e) and 4(f)), resulting in either an increase or a decrease in photocatalytic properties. An important feature is detailed system modeling and prediction of applied characteristics against titanium dioxide-PSS-PEI hybrid and its architecture.

Titania is a good model semiconductor for studying the light- $\mathrm{pH}$ coupling effect due to its photocorrosion resistivity, stability and having one of the best-studied surface state chemistry in correlation with the surrounding medium. However, there are several other semiconductors (Table 1, Figures 4(g) and 4(h)). In Figures $4(\mathrm{~g})$ and $4(\mathrm{~h})$, it is highlighted that a PV element based on a zinc oxide/perovskite photoactive part in combination with PEI has $J_{\mathrm{sc}}=15.6 \mathrm{~mA} / \mathrm{cm}^{2}{ }^{45-47}$ Other polyelectrolytes were not tested, and even the role of PEI was not properly discussed for a predictive model. However, taking into account aforementioned facts, the probability of finding a proper nanoarchitecture for exploitation of perovskite and III-V semiconductor-based elements is high. 


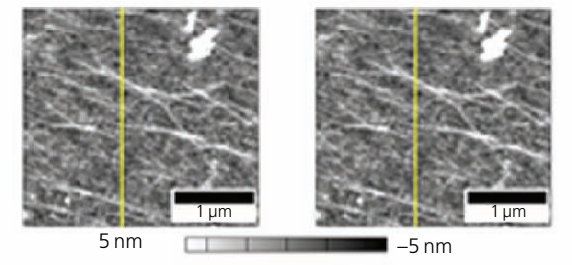

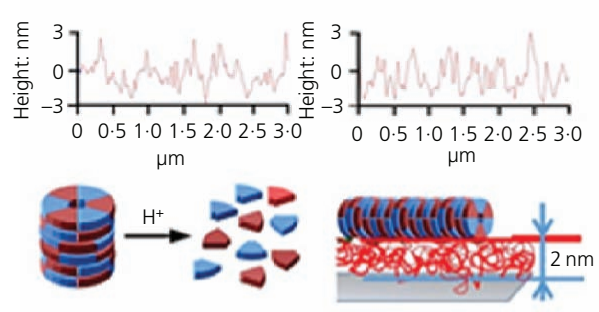

(a)
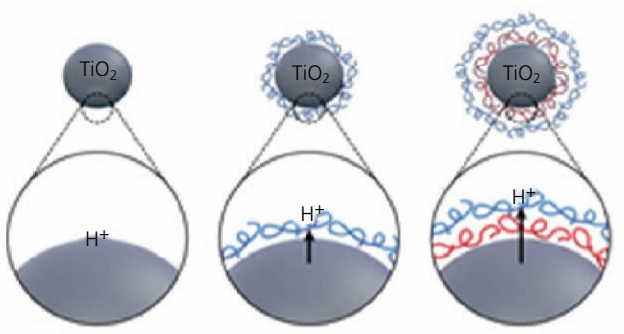

(c)

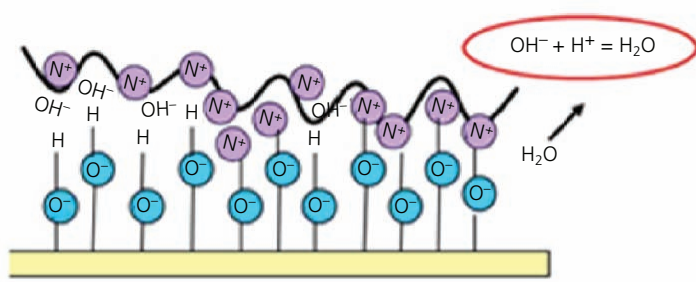

(e)

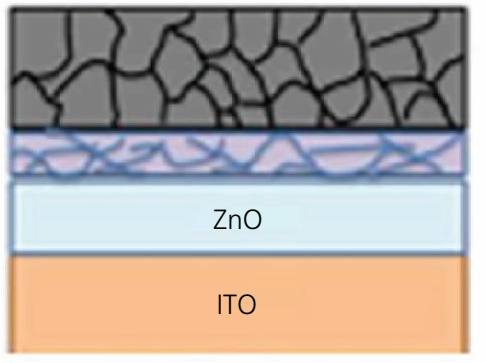

(g)

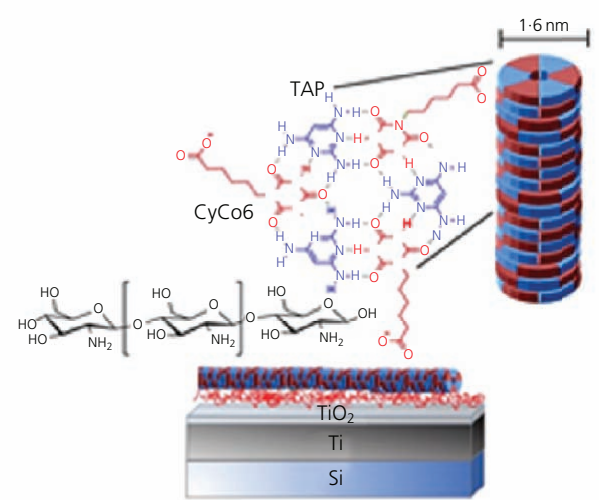

(b)

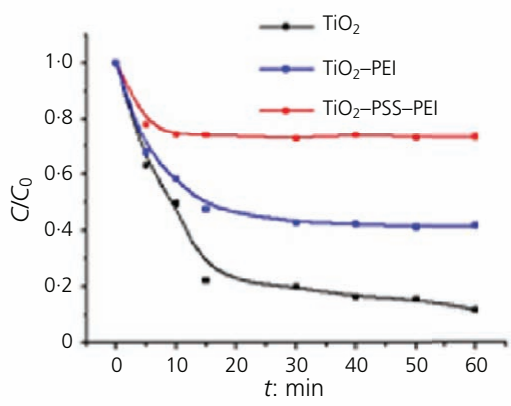

(d)

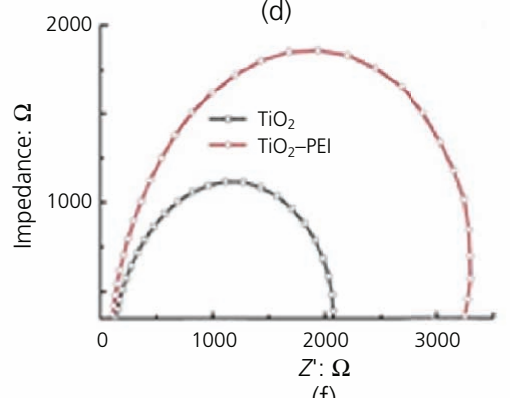

(f)

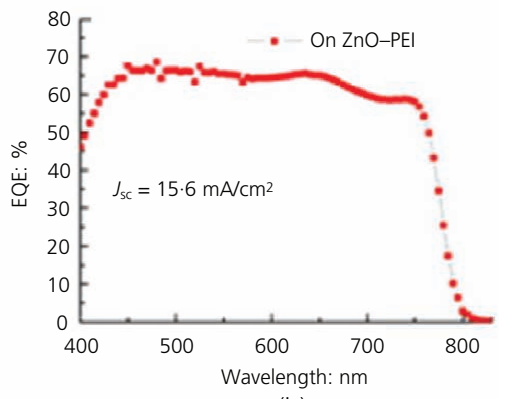

(h)

Figure 4. Effects of a nanometer-thick polyelectrolyte layer on semiconductor properties: (a, b) A $2 \mathrm{~nm}$ chitosan layer on the titania surface is efficient as a proton sponge, and no disassembly of the CyCo6-TAP complex was observed due to change of surface acidity (CyCo6, cyanuric acid modified with hexanoic acid side chain; TAP, triaminopyrimidine). Adapted from Andreeva et al. ${ }^{43}$ (c, d) Highlight of the importance of the position of the polyelectrolyte proton sponge layer (here, PEI) in the interface of titania and LbL assembly of PEI and PSS, resulting in drastically different photoactivity. Adapted from Brezhneva et al. ${ }^{44}$ (e, f) PEl also affects impedance and is used for modification of solar cells (adapted from Schouten et al., ${ }^{45}$ Muderrisoglu et al. ${ }^{46}$ and Li et al. ${ }^{47}$ ), including $(\mathrm{g}, \mathrm{h}$ ) solar cells based on perovskites (adapted from Cheng et al. ${ }^{41}$ ). EQE, external quantum efficiency 
The study of solar energy conversion and photoinduced bioactive sensors represents leading scientific fields, where interfaces play a decisive role for efficient applications. The key to tuning these interfaces specifically is a precise knowledge of interfacial structures and their formation on the microscopic, preferably atomic, scale. Supplie et $a l^{5}$ discussed how the area of III-V semiconductor development can be regarded within the frame of bioapplications and sensors. Supplie et al. ${ }^{5}$ describe appropriate analysis techniques capable of monitoring critical physicochemical reactions in situ during non-vacuum preparation and photoactivity studies including well-defined inorganic epitaxial reference surfaces, buried interfaces and low-defect nucleation of disjunct epitaxial materials that were analyzed during preparation in a chemical vapor environment. In addition, the complex coupling of inorganic stable photoactive materials with responsive soft matter for bioactivity was also under consideration.

Enzymatic reactions can be also controlled using the light-pH coupling phenomenon. Surface modification by an enzyme allows achieving affinity and improving the biological response of bioinert surfaces. Experiments with osteoblasts demonstrated that the higher cell viability of a titanium implant surface functionalized by a polyelectrolyte-enzyme interface favors the osteogenic response. ${ }^{45,46}$ Stimulus-responsive biointerfaces open perspectives to smart-material-based tissue engineering. Thus, the formation of trypsin from its precursor trypsinogen was chosen as an example of a $\mathrm{pH}$-sensitive autocatalytic enzymatic reaction and was studied on a titanium dioxide-PSS-PEI hybrid and the titanium dioxide surface as a control. ${ }^{50}$ The results indicated that the acidification of the surrounding media near the pristine titanium dioxide is the most possible explanation of the suppressed formation of trypsin in comparison with that in the hybrid system. In the latter case, the adsorption of trypsin was higher in comparison with that with pure titanium dioxide; however, polyelectrolyte layers deposition had less effect on the autocatalytic enzymatic reaction. Thus, varying the position of the polyelectrolyte layer in the LbL assembly can serve as an easy method of tuning the hybrid system photoactivity.

\subsubsection{Complex thinking for switching biological response}

The complex interactions of PMs with living objects, such as bacterial and yeast and human cells and tissues, are being discussed more and more. The proper design of drug delivery systems, as freestanding or surface capsules, ${ }^{51-56}$ is a topic of high importance. The authors shall further focus on the following questions: $(a)$ what a proper carrier is; (b) what type of chemistry is suitable for communication; (c) how to design two-sided communication - that is, processing of signals is performed by both the cell signaling network and synthetic chemical network; and $(d)$ how to influence cells - for example, bacteria - with synthetic chemistry and how synthetic chemistry can response to bacteria.

In Figure 5(a), an example of a titania-based capsule for lightstimulated delivery of chemical species is shown, ${ }^{57}$ and in Figure 5(b) it is pointed that bacterial metabolism has feedback mechanisms. ${ }^{58}$ Nowadays there are many attempts to add chemical signals for biological signaling for various applications, from diagnosis and treatment of illnesses to modeling the understanding of complex system behaviors. In a recent work of Nikitina et al., ${ }^{59}$ a new contribution to the design of polyelectrolyte capsules based on surface-modified mesoporous titania particles with deposited silver (Ag) nanoparticles to achieve chemical light upconversion by way of biofilms was shown (Figures 5(c) and 5(d)). The polyelectrolyte shell allows slowing down the release kinetics of loaded L-arabinose and switching the bacterial luminescence in a certain time. The hybrid titanium dioxide-silver-polyelectrolyte capsule activated at $980 \mathrm{~nm}$ (infrared (IR)) illumination demonstrated ten times faster release of L-arabinose as opposed to non-activated containers. Fast IR release of L-arabinose switched bacterial fluorescence, which the authors monitored at $510 \mathrm{~nm}$. The approach described herein can be used in many applications where delayed switching and light upconversion are required. Such complex thinking is very important for integration of complex chemical networks with biological networks - enzymatic networks, ${ }^{50,60-63}$ bacterial quorum sensing ${ }^{64-66}$ and synthetic biology ${ }^{67-69}$ - suggesting them as one working reaction network.

Gradient processes on the surface of irradiated semiconductorpolyelectrolyte hybrids can also play an important role in the regulation of cell behavior. Recently, the dynamics of preosteoblast growth on the surface of mesoporous titanium dioxide with deposited layers of block-copolymer micelles (BCMs) and poly(acrylic acid) (PAA) has been investigated. ${ }^{70}$ The consequence of $\mathrm{pH}$ alteration after irradiation of the system was a change in the polymer film stiffness - in the acidic media, the micelles swelled and drastically changed the thickness and the Young modulus of the polymer coating (Figure 6). Earlier, the change in $\mathrm{BCM}$ properties under $\triangle \mathrm{pH}$ resulting from the bacterial vital activity was investigated. ${ }^{71}$ For the LbL assembly of polyelectrolytes without titanium dioxide coating, a change in the stiffness under irradiation did not occur and the coating remained rigid. During $5 \mathrm{~d}$ of cultivation, the cells had a tendency to migrate from the 'soft' part of the sample toward the 'stiff' one (Figure 6). Thus, the manipulation of the mechanical modulus of the hybrid coatings can lead to the fabrication of stimulusresponsive materials for biological purposes.

Light is an attractive stimuli for the regulation of the gradient in time and space. It is easy to vary its intensity, duration and wavelength. However, in many cases, fundamental understanding of red/ox processes is needed. Studies of the electrochemical behavior of systems provide information about the quantity of the transferred electrons and processes at the electrodes.

\subsection{Electrochemical studies of electrode-polyelectrolyte interfaces}

2.2.1 Importance of multicycle behavior

Electrochemical cells usually consist of two electrodes immersed in a solution (liquid or solid) of electroactive species in 


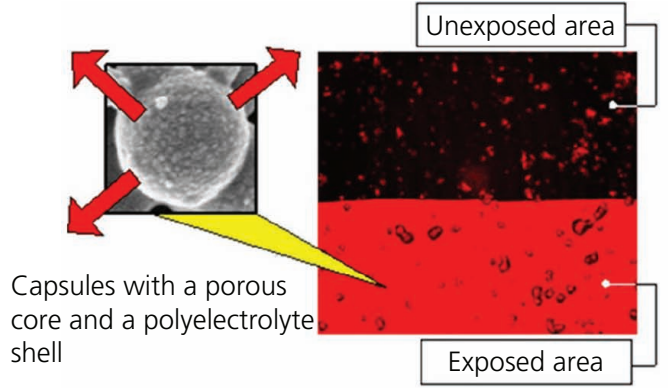

(a)

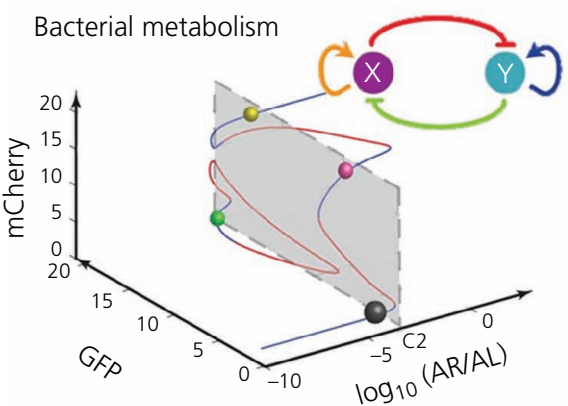

(b)

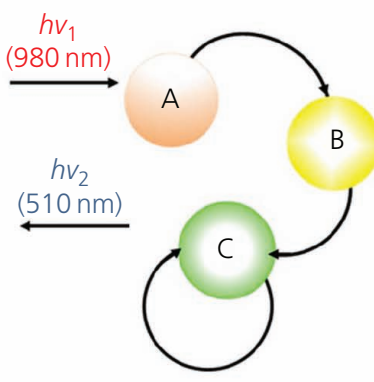

(c)

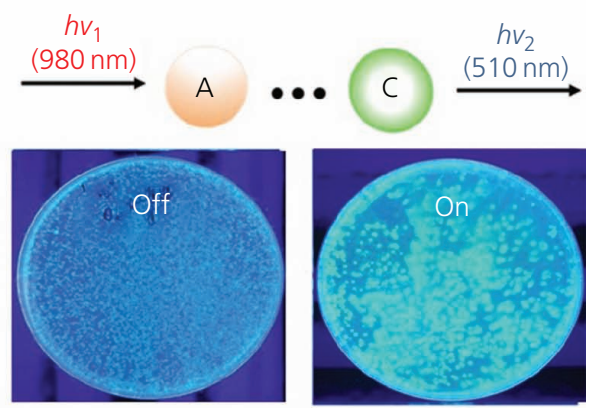

(d)

Figure 5. Complex thinking of polyelectrolyte capsules for switching biological response. (a) Titania capsules with a polyelectrolyte shell can be used for local light-stimulated delivery. The confocal image presents capsules loaded with rhodamine 6G and entrapped in a sol-gel matrix which releases the dye only in exposed areas. Adapted from Skorb et al. ${ }^{57}$ (b) Bacterial metabolism is presented as having a non-linear start due to starting the fluorescence of green fluorescent protein (GFP) in response to L-arabinose activation. Adapted from Wu et al. ${ }^{58}$ (c, d) A block schema of experiments where capsules $(A)$ are nanostructured to release the needed concentration of L-arabinose (B) and switch bacteria metabolism (C), for use as a marker for switching of the fluorescence at $510 \mathrm{~nm}$, which can be monitored by various methods. Shown here are photographs of petri dishes in off and on cycles. Adapted from Nikitina et al. ${ }^{59}$ AR/AL, androgen receptor fluorescence

conductive media (electrolyte). The anode is where the oxidation reaction occurs, and the cathode is where the reduction reaction takes place. Since the fact that most electrochemical systems are heterogeneous, electrode reactions are related to electron transfer through the electrode-electrolyte interface. Thus, the characteristics of an electrode reaction are highly affected by the microstructure of the electrode surface, its cleanness, surface physics and chemistry. The non-faradaic impact of current flow is largely related to adsorption/desorption processes, solvent dipole reorientation and so on. Thereby, interfacial processes are of high importance in electrochemical systems.

LbL PEMs are traditional and ubiquitous components in designing interfaces with special properties. Recent progress in science provides understanding of fundamental principles of polyelectrolyte complexation and particle encapsulation due to electrostatic interactions.

As a result of the high ionization degree of polyelectrolytes, their deposition is a versatile and universal approach to creating the desired net charge on a surface. Concerning electrochemical applications, it is an attractive possibility to increase electrode selectivity and sensitivity as far as PEMs deposited on the top of the electrode surface form a strong electrostatic barrier to species of the same charge. Recently, it was demonstrated that the permeability of polyelectrolyte films depends mostly on film composition rather than its thickness, and three different modes of interaction between PEMs on the top of electrodes and model electrochemical probes were observed - permeability, nonpermeability and ion accumulation. ${ }^{72}$

For photochemical system, the light-pH coupling was discussed in detail earlier. For electrochemical systems, proton generation can be associated with hydroquinone oxidation (Figure 7(a)). Ryzhkov et $a l^{73}$ in their work studied proton generation on electrodes using the in situ scanning vibrating electrode technique (SVET) (Figures 7(b)-7(d), 7(k) and 7(m)), SIET (Figures 7(e), $7(\mathrm{f}), 7(\mathrm{l})$ and $7(\mathrm{n}))$ and electrochemical impedance spectroscopy (EIS) (Figures $7(\mathrm{~g})$ and $7(\mathrm{~h})$ ).

The methods are suggested to be powerful instruments for the in situ observation of reversible processes associated with the lipid bilayer (LB)-solid support interface (Figures 8(a)-8(c)). EIS highlighted the reversible disappearance of the LB's impact on impedance in acidic conditions set by dilute acid addition as well as by electrochemical proton release on the gold $(\mathrm{Au})$ electrode due to hydroquinone oxidation. In situ studies of transmembrane channels often require a model bioinspired artificial LB decoupled from its underlying support. Obtaining freestanding lipid membranes is still a challenge. Ryzhkov et al. ${ }^{73}$ suggested an 

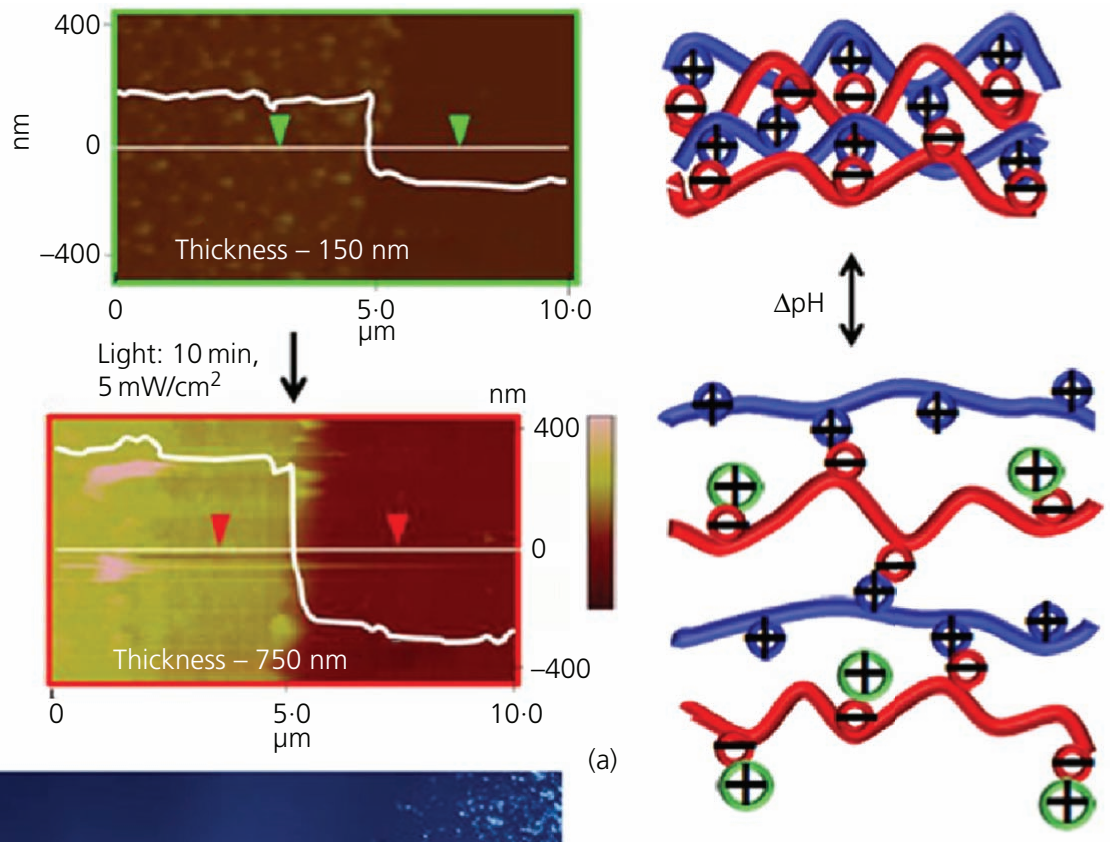

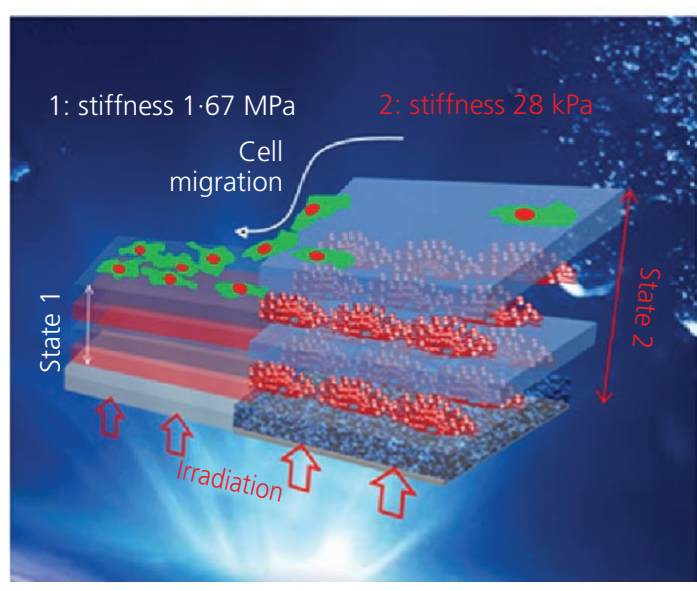

(b)

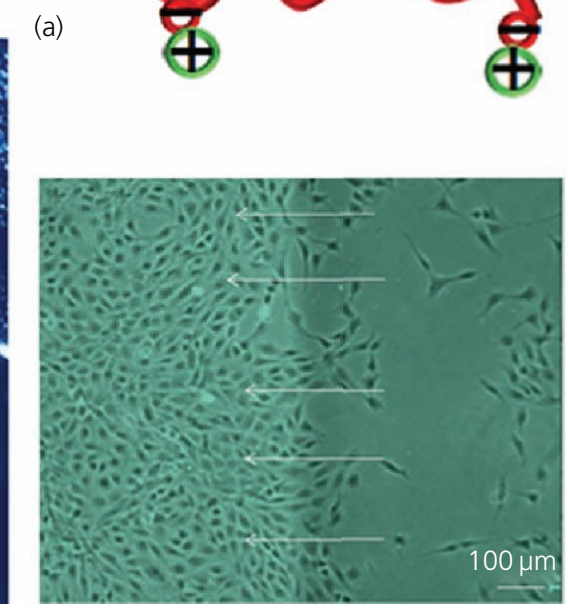

(c)

Figure 6. Example of photoswitchable LbL assembly for bioapplication. (a) Atomic force microscopy images and schematic illustration of change in LbL thickness in response to irradiation (intensity of $5 \mathrm{~mW} / \mathrm{cm}^{2}$ ) show a change in thickness from 150 to $750 \mathrm{~nm}$ as well as stiffness from 1.67 to $28 \mathrm{kPa}$. Adapted from Ulasevich et al. ${ }^{71}$ (b) Suggestion of use of such photoregulated lab-on-a-chip in (a) to guide cell migration and (c) corresponding cell (osteoblast MC3T3-E1) migration experiment; note that, before irradiation, the numbers of cells were equal on both sides. Adapted from Ulasevich et al. ${ }^{70}$

electrochemical approach to LB separation from its solid support by way of hydroquinone oxidation. LbL deposition of PEI and PSS on a gold electrode was performed to obtain a polymeric nanocushion of $[\mathrm{PEI}-\mathrm{PSS}]_{3}-\mathrm{PEI}$. The LB was deposited on the top of an underlying polymer support from the dispersion of small unilamellar vesicles due to their electrostatic attraction to the polymer support. Since lipid zwitterions demonstrate $\mathrm{pH}$-dependent charge shifting, the separation distance between the polyelectrolyte support and LB can be adjusted by changing the environmental $\mathrm{pH}$, leading to recharge of lipid molecules.

The outermost layer determining the net charge of the polyelectrolyte layer plays a crucial role in permeability properties of multilayered assembly completely blocking the diffusion of charged electroactive species. As it was demonstrated for $\mathrm{pH}-$ dependent charge-shifting electroactive species, permeability can be switched to non-permeability when the isoelectric point is crossed and the electroactive specimen involved in the electrode reaction becomes of the same charge as a terminating layer of the LbL assembly on the top of the electrode. ${ }^{77}$ A similar behavior was observed when the outermost layer of a polyelectrolyte assembly was presented by molecule turning from being positively charged at $\mathrm{pH} 3$ to negatively charged at $\mathrm{pH} 10$ (Figures 8(d)-8(f)). Positive and negative electrochemical probes, $\left[\mathrm{Ru}\left(\mathrm{NH}_{3}\right)_{6}\right]^{3+}$ and $\left[\mathrm{Fe}(\mathrm{CN})_{6}\right]^{3-}$, demonstrate a switch from the permeable regime to the non-permeable one and vice versa, respectively, shifting from basic to acidic condition. ${ }^{78}$ PEMs of poly(diallyldimethylammonium chloride) (PDDA) and 


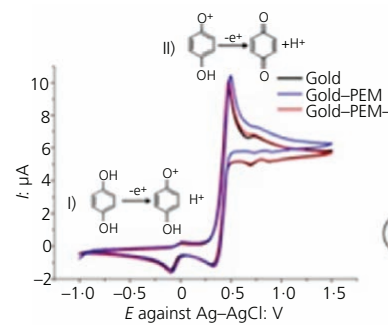

(a)

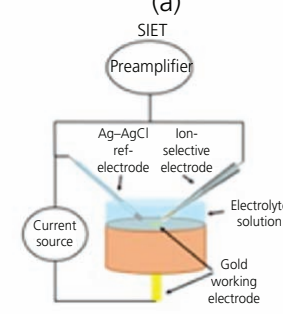

(e)

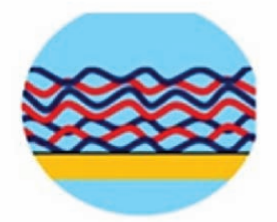

(i)

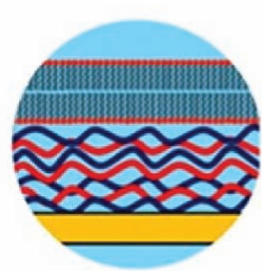

(l)

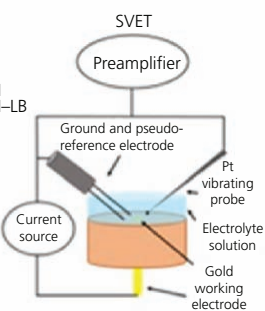

(b)

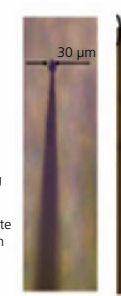

(c)

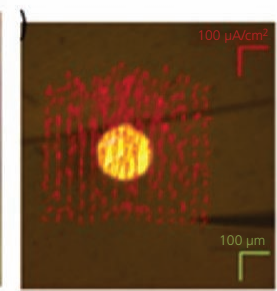

(d)

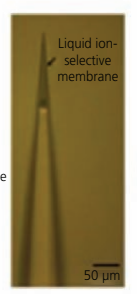

(f)

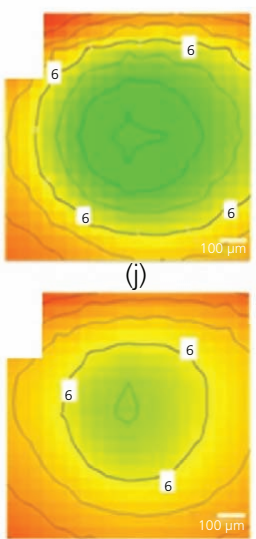

(m)

(g)
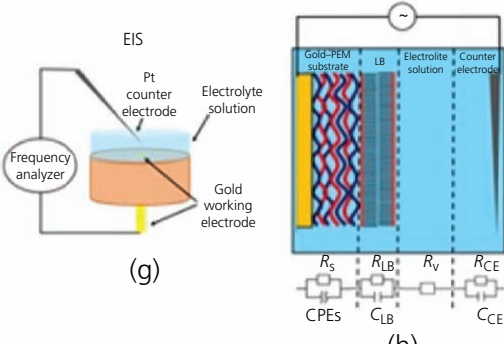

(h)

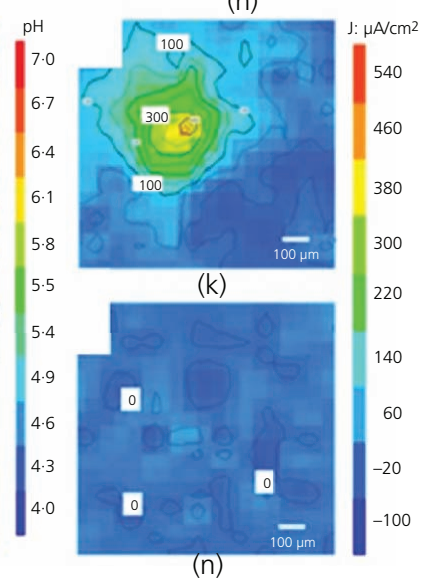

Figure 7. Possible methods and corresponding data for in situ spatiotemporal monitoring of feedback responses on a nanostructured surface. (a) Cyclic voltammetry curves of hydroquinone on a pure gold electrode and a gold electrode covered by a PEM and polymer-cushioned LB. (b) Scheme of SVET measurement. (c) Platinum (Pt)-iridium (Ir) vibrating probe. (d) Top view of the gold wire embedded in the epoxy holder. Red arrows represent ionic currents measured by SVET. The platinum vibrating electrode is seen at the right bottom of the image. (e) Schematic diagram of SIET measurement. ( $f$ ) Glass capillary microelectrode with liquid ion-selective membrane. (g) Schematic diagram of EIS measurement. (h) Equivalent electrical scheme representing parts of the electrochemical system with the gold electrode covered by a PEM and a LB.

(i-n) Schematic representation of the electrode structure; map of adjusted $\mathrm{pH}$ of electrode media after $5 \mu \mathrm{A}$ current was passed through the electrode immersed in a $60 \mathrm{mM}$ hydroquinone solution in $150 \mathrm{mM}$ potassium nitrate $\left(\mathrm{KNO}_{3}\right)$, as measured by SIET; and anodic activity of the electrode immersed in a $60 \mathrm{mM}$ hydroquinone solution in $150 \mathrm{mM}$ potassium nitrate while $5 \mu \mathrm{A}$ current was passed, as measured by SVET, for $(i, j, k)$ gold-PEM and $(I, m, n)$ gold-PEM-LB electrodes, respectively. Adapted from Ryzhkov et al. ${ }^{73}$

poly(4-styrenesulfonic acid-co-maleic acid) (PSS-MA) with strong and weak anionic groups become completely impermeable for both cationic and anionic probes at high $\mathrm{pH}$ and permeable for negative species in acidic conditions. ${ }^{79}$

Another regulation by light of the $\mathrm{pH}$-sensitive complex adsorption/desorption process was shown in an example of protein tagged with the amino acid histidine amino acid (polyHis-tag) with a nickel (Ni)-nitrilotriacetic acid (NTA) complex where the last component was in the LbL assembly on the titanium-based chips covered with native titania ${ }^{75}$ (Figures $8(\mathrm{~g}$ ) and $8(\mathrm{~h})$ ). The interactions of the poly-His-tag protein with
nickel-NTA are $\mathrm{pH}$ sensitive. Short-term irradiation was used for switching the $\mathrm{pH}$ value of the subsurface surrounding media. After turning the light on, the $\mathrm{pH}$ value changed to 4 and the dissociation of $\mathrm{NTA}-\mathrm{Ni}^{2+} / \mathrm{His}-\mathrm{Tag}$ occurred and the protein desorped from the surface, which was confirmed by confocal laser fluorescence microscopy and quartz crystal microbalance analysis. Turning the light off resulted in the reverse process - adsorption of the protein to the surface. Thus, light regulation of protein sorption can have biosensing and biomedical applications.

The outermost polyelectrolyte layer of a multilayer determining its net charge plays a significant role in the interaction with 


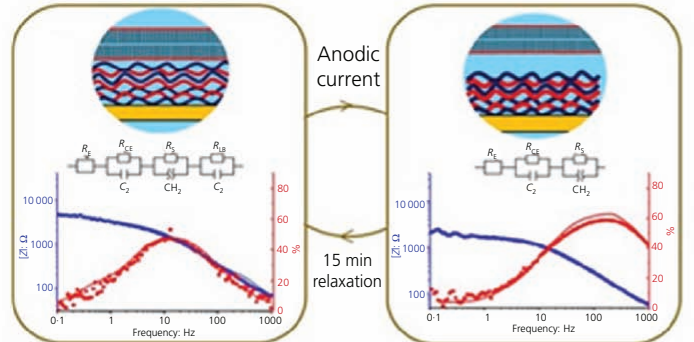

(b)

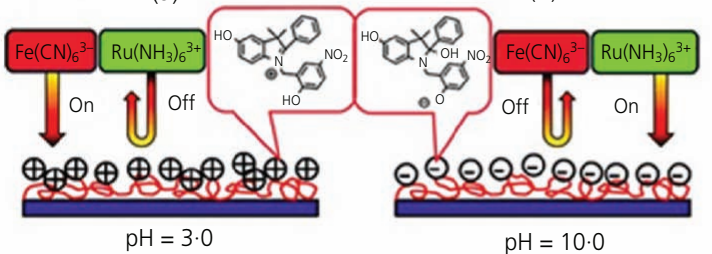

(e)

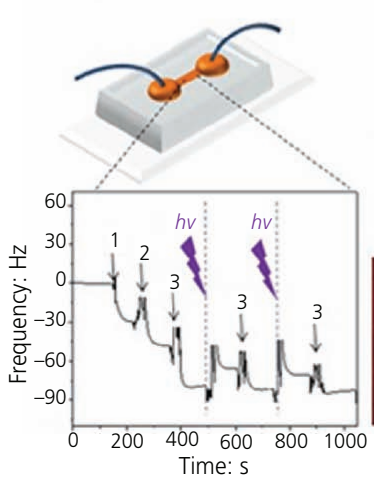

(g)

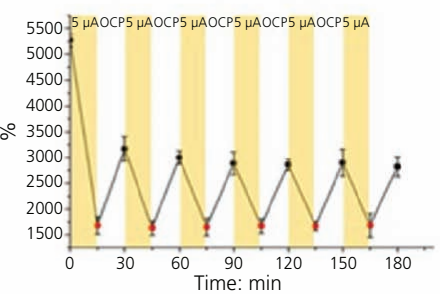

(c)

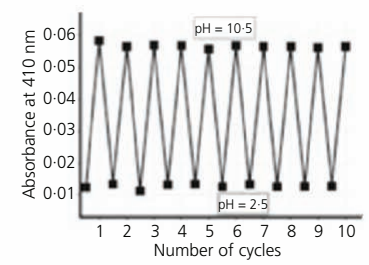

$(\mathrm{f})$

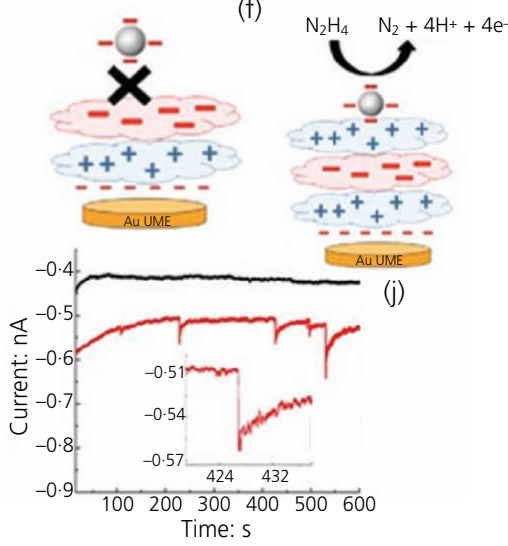

(i)

Figure 8. Examples chosen to highlight multicycle switching. (a, b) Impedance spectra of titanium dioxide-PEM-LB composites. The red curves are nine overlapping spectra registered in darkness immediately after 20 min of illumination; the blue curves are nine overlapping spectra registered after 20 min of relaxation in darkness. (c) Impedance oscillations during irradiation on-off cycles. Adapted from Ryzhkov et al. ${ }^{73}(\mathrm{~d}-\mathrm{f}) \mathrm{pH}$-dependent switching of electroactive LbL-based assembly. Adapted from Pennakalathil et al. ${ }^{74}(\mathrm{~g}, \mathrm{~h}$ ) Quartz crystal microbalance monitoring of adsorption and desorption on a chip of His-tag protein with corresponding confocal images of the surface with protein and without. Adapted from Andreeva et al. ${ }^{75}$ Parts (i) and (j) highlight the possibility of having a reactive side against the activated state of PEM. Adapted from Castañeda et al. ${ }^{76}$

charged colloidal particles. If an experiment is performed in the solution of an electroactive specimen, every collision of a conductive particle with the PEM on the top of the electrode is followed by electron transfer. In the study of Pennakalathil et al. ${ }^{74}$ hydrazine oxidation was performed on poly-L-lysine (PLL)-poly-L-glutamic acid (PGA)-covered gold electrode in a dispersion of gold nanoparticles. Every collision of a nanoparticle with the PEM-covered electrode was followed by a current spike (Figures 8(i) and 8(j)).

Recent studies also aimed to reveal temperature and ionic strength effect on diffusion through PEMs. ${ }^{80}$ The exact nature of ion transport through PEMs was discovered to be similar to the one through solid matter and coupled to the motion of the surrounding polyelectrolyte chains. Thus, this process is thermoactivated as it was shown for PDDA-PSS multilayers. ${ }^{80}$ Electrode modification by thermoresponsive polymer brushes that transform to a collapsed state during heating demonstrated simultaneous decrease in resistivity. ${ }^{81}$ This approach can be used in the design of thermoresponsive switchable electrochemical sensors.

It was also shown that diffusion of the electroactive species to the electrode through polyelectrolyte layers can be significantly influenced by the nature of the supporting electrolyte. ${ }^{82}$ EIS revealed that, for polyelectrolyte brushes grafted to the electrode surface, an increase in the salt concentration led to the collapsed state of the polymers, which blocked electron transport and decreased the conductivity of the composite. Nevertheless, swollen brushes allow good permeability of electroactive probes. $^{83}$ 
The aforementioned possibilities to change the permeability of the polymer layers on the top of the electrode surfaces open great perspectives on the design of electrochemical sensors with regulated selectivity, sensitivity and response time. This approach has been developed mainly in the design of amperometric biosensors. Due to the selective permeation of the target specimen through a PEM film of PAA/poly(vinyl sulphate) nanoarchitecture, the selectivity of the platinum $(\mathrm{Pt})$ electrode to hydrogen peroxide $\left(\mathrm{H}_{2} \mathrm{O}_{2}\right)$ in the presence of organic acids increased significantly. ${ }^{84}$ Complete suppression of charged oxidizable compounds' permeability can be achieved by altering the number of the assembled layers. Modified electrodes semipermeably selective to hydrogen peroxide are suggested to be an attractive platform for glucose $^{85}$ and uric acid biosensors. ${ }^{86}$

It is now well recognized that nanoscale materials present significant enhancement in catalytic and sensing properties compared to bulk ones of the same composition. Thus, decoration of electrodes by metal nanoparticles draws much attention nowadays. LbL assembly, being a versatile and simple instrument of surface modification, is widely used for enhancing electrode efficiency due to nanostructuring. ${ }^{87}$ Multilayered assemblies of PDDA and gold nanoparticles demonstrated a good response for arsenic (III) $\left(\mathrm{As}^{3+}\right)$ compounds, thus providing an opportunity for biosensor applications. ${ }^{88}$ Recently, it has been reported that PEMs containing gold nanoparticles may exhibit stimulus-tunable electric conductivity. It was also demonstrated that the function of polyelectrolyte layers is not limited by particle immobilization. It was shown that humidity-responsive swelling of polyelectrolyte chains between encapsulated particles led to larger distances and lower electron tunneling probabilities. ${ }^{89}$ It is important to note that conductivity may be both predetermined by deposition conditions and be changed while exploiting under external stimuli. The electrochemical response of multilayered assemblies of the charged polymer molecules and metal nanoparticles is significantly affected by the morphology of polymer layers. If multilayers of PSS-poly(allylamine)ferrocene (PA-FC) are organized in stratified layers, electron transport happens through the electron hopping from one metal particle to another separated by non-conductive polymer layers. In PGA-PA-FC multilayers, polyelectrolyte molecules are free to diffuse and their movement results in making metal impurities come in contact with each other and the electrode, enhancing electron transport and increasing the conductivity of the composite. In cross-linked PGA-PA-FC multilayers, the polyelectrolytes are no longer able to diffuse and electron transfer in these multilayers happens as in the case of PSS-PA-FC through electron hopping from one metal particle to another. ${ }^{90}$ Thus, three different regimes of electron transfer can be observed from the electroactive specimen in solution to the electrode through the complex interfaces.

Another way to enhance electron transfer through polyelectrolyte layers is introducing specially modified polymers with electroactive moieties into the multilayered LbL assemblies. Poly(4-vinylpyridine) with a covalently attached osmium complex was suggested to be an electron transfer agent in a polyelectrolyte-lipid bioinspired composite. ${ }^{91}$ Multilayers of PLL-PGA covering a gold electrode enhance electron transfer and induce increase in faradaic current without any introduction of the electroactive specimen into the multilayer structure. ${ }^{76}$ Carbon nanotubes modified by PDDA layer demonstrated an increased catalytic performance to oxygen reduction similar to that of platinum catalysts. The main reason of such composite behavior was the strong electron-withdrawing ability of the polymer. $^{92}$

In many cases, polyelectrolyte layers serve as a material that modulates the electrochemical response of the electrode. However, polyelectrolyte assemblies on the top of the electrode also serve as 'smart' dynamic materials responsive to electrochemical stimuli. Charged polymer molecules are highly sensitive to the surroundings. It is well known that they change conformation from linear to coiled during, for example, an increase in the ionic strength. Electrochemical control over the morphological transitions of polyelectrolytes is very attractive for guiding biological morphogenesis. A reversible thickness increase of about $5-10 \%$ may be reached through the penetration of chloride ions into the PEM resulting from $\left[\mathrm{Fe}(\mathrm{CN})_{6}\right]^{4-}$ reduction and consequent appearance of non-compensated positive charges. $^{93}$ This phenomenon was used to demonstrate timeresolved control over the wettability of electrochemically addressable surface of polycationic poly(2-(methacryloyloxy) ethyltrimethylammonium chloride) (PMETAC) brushes with ferricyanide ions. Alternating application of negative and positive potentials induces reversible switches of PMETAC brushes between linear and coiled states simultaneously with the reduction and oxidation of $\left[\mathrm{Fe}(\mathrm{CN})_{6}\right]^{3-}$ and $\left[\mathrm{Fe}(\mathrm{CN})_{6}\right]^{4-}$. As a result, reversible changes in water contact angles may be observed. ${ }^{94}$ It is well known that strong electric fields can promote dissociation of weak polyelectrolytes. Ionization of weak polyelectrolytes assembled on the top of the electrode surface under applied potential leads to enhanced intramolecular repulsion between the charged moieties of polymer molecules, which can promote conformational change. As a result, the switch from hydrophobic to hydrophilic state and vice versa can be performed. The swelling behavior of polystyrene-block-PAA under a negative bias led to an increase in the water contact angle. ${ }^{95}$ Swelling and deswelling of polyelectrolyte layers under alternating applied potential can reversibly bend underlying supports due to conformational changes of polymers. A simple and versatile platform for electroactuation was demonstrated by employing a cantilever modified by PMETAC brushes, ${ }^{96}$ Nanoactuation of PGA-poly(allylamine hydrochloride) (PAH) and carboxymethyl cellulose (CMC)-PDDA multilayers in similar conditions by potential application was also demonstrated. ${ }^{97}$ It is interesting that ferrocyanide oxidation caused the swelling of PGA-PAH multilayers, whereas CMC-PDDA multilayers underwent contraction due to the presence of a positive and a negative Donnan potential, respectively. In the case of multilayers assembled from weak polyelectrolytes, morphological transitions 
may originate from $\mathrm{pH}$ change induced by water hydrolysis after potential application. Structural rearrangements of the weak polyelectrolyte molecules in an electrically induced $\mathrm{pH}$ gradient can lead to the creation of a porous structure. ${ }^{98}$

Although initially only artificial polyelectrolytes were suggested for LbL modification of electrodes, nowadays significant efforts are being made to expand this approach to biocompatible materials. Thin films of chitosan biopolymer susceptible to chemical modification by way of reactive functional groups were investigated due to several aspects. The first one is the switching net charge of the polymer film on the top of the electrode, and the second one is introduction of charge-based chemical recognition to amperometric sensors. ${ }^{99}$ Modification of electrodes with biocompatible materials is a critical point for designing safe and reliable tissue-electrode interfaces of neuroprosthetic and cardiostimulating electrodes. Platinum electrodes modified by alternating layers of carbon nanotubes and poly(vinyl acetate) can serve as a new material for neural interfacing and significantly outperform materials available today in terms of electrochemical stability, low impedance and charge storage capacity. ${ }^{100}$ Proteins and ferments assembled in multilayers on the top of electrodes have ushered a new era of electrochemical biosensors. Alternatively, immobilized poly(sodium 4-styrenesulfonate) and horseradish peroxidase (HRP) on zinc oxide nanorods exhibited a wide linear range and low detection limit of hydrogen peroxide without any electron transfer mediator. ${ }^{101}$

Another biocompatible hydrogen peroxide sensor based on HRP was assembled with a deoxyribonucleic acid (DNA) network. The last one greatly amplified the coverage of HRP molecules on the electrode surface and facilitated the charge carriers enhancing the electron transfer between HRP and the electrode. The biosensor showed fast response, high sensitivity, good reproducibility, long-term stability and an extremely low detection limit. ${ }^{102}$ Direct electron transfer was observed for glucose oxidase immobilized on titanium dioxide. A glucose sensor with high sensitivity, low detection limit, good selectivity and long-term stability can be obtained without a mediator. ${ }^{103}$ Experimental results showed that polyelectrolyte-stabilized colloidal gold can be used as a biocompatible matrix for enzyme immobilization. ${ }^{104}$ It was demonstrated that chitosan-stabilized gold nanoparticles deposited on the top of a gold electrode enhanced the electron transfer ability. Protein molecules of myoglobin, hemoglobin and cytochrome $\mathrm{c}$ assembled on the top of these electrodes displayed an excellent electrocatalytic performance to the reduction of hydrogen peroxide and were stable as long-term sensors with reproducible measurements. ${ }^{105}$ A densely packed gold nanoparticle platform combined with a multiple-enzyme-labeled detection antibody-magnetic bead bioconjugate was used as the basis for an ultrasensitive electrochemical immunosensor to detect cancer biomarkers in serum. ${ }^{106}$

Electrochemically triggered self-assembly of charge-shifting polyelectrolytes in nanoscale multilayers was demonstrated for many systems. ${ }^{107}$ For example, an electrochemically generated $\mathrm{pH}$ gradient leads to the hydrolysis of anionic dimethylmaleicmodified $\mathrm{PAH}^{108}$ or citraconic-modified $\mathrm{PAH}^{109}$ to cationic $\mathrm{PAH}$ and its consequent assembly with anionic PSS.

Since polyelectrolyte assemblies are held together on the basis of electrostatic interaction, their stability is highly sensitive to influencing electrical fields. As reported by Zahn et al., ${ }^{110}$ release of DNA encapsulated in PEMs was triggered by the application of electrochemical potential. In the study of $\mathrm{Si}$ et al., ${ }^{111}$ calcein from vesicles embedded in polyelectrolyte layers was released and delivered to viable cells on the top of the assembly upon the application of an electrochemical stimulus.

A biocompatible method of selective detaching of threedimensional cell-encapsulated hydrogel from a culture substrate was reported. ${ }^{112,113} \mathrm{LbL}$ assembly of PLL-hyaluronic acid with methacrylated chitosan on its top was deposited on an indium tin oxide (ITO) substrate. Heparin-based hydrogel fabricated on the top of the composite described earlier was detached by dissolution of the underlying PEM when applying an oxidative potential. The applied potential did not affect the viability or the function of the cells in the entire hydrogels.

To sum up, concerning the electrochemical aspects, LbL deposition of PEMs is a simple ways nanostructuring electrode surfaces. These complex structures can play an important role not only in tuning the structure of the electrodes on which surface they were deposited, but also in creating novel smart stimulusresponsive materials. External stimuli (electric field) to electrode-PEM hybrids can serve as a trigger for various processes - reversal switch of surface wettability, self-assembly of polyelectrolytes, release of the encapsulated substance and detachment of cell-encapsulated hydrogel. Thus, the diversity of the electric stimulus responses of such nanostructured hybrid material can find applications for biosensing, nanoactuation platforms and so on.

\subsubsection{Photoelectrochemical applied devices}

Taking into account the potential of polyelectrolyte layers for application in photoelectrochemical device fabrication, one should note that they can play an important role as templates for oxide semiconductor or metal film preparation. ${ }^{114,115}$ Particularly, Lowman et al. ${ }^{115}$ used LbL assembly of linear PEI and PAA as a framework for titanium dioxide porous layer preparation for the fabrication of dye-sensitized solar cells (DSSCs). The PEI layer can play an important role in the formation and growth of continuous, ultrasmooth and highly conductive silver coating for light-emitting diodes, photodetectors and optoelectronics. ${ }^{116}$

The combination of BCMs with PAA layers can be actuated by the $\mathrm{pH}$ gradient on the irradiated semiconductor surface described in the previous section. In the study of Lanchuk et al. ${ }^{117}$ the reaction of photoelectrochemical water splitting was used as the trigger for the actuation of deposited weak polyelectrolytes. 
The illumination of the semiconductor with supraban energies causes the formation of photoelectrons and photoholes on the surface, followed by scavenging of oxygen molecules and surface hydroxyl groups, respectively. The photogenerated protons determine local acidification of the surface layer, which was confirmed by $\mathrm{pH}$ mapping by SIET. ${ }^{42}$ The $\mathrm{pH}$ decrease leads to changes in the thickness and stiffness of the weak polyelectrolyte assembly; after fast switching, the system exhibited slow relaxation, which can potentially find applications in designing biomimicking materials.

A large number of papers are dedicated to the exploitation of semiconductor-polymer hybrid structures that can be used as an intermediate layer in organic or perovskite solar cells for their efficiency improvement. ${ }^{118-123}$ One of the requirements for the efficient functioning of solar cells is the minimization of the barriers for charge transport across the active layer-electrode interface. Aliphatic polyelectrolytes containing amine groups (PEI and ethoxylated PEI (PEIE)) can be employed as an electron transport layer (ETL) to reduce the work function of the ITO and the interfacial energy barrier so as to facilitate the electron transfer between the active material and the electrode.

The deposition of PEI and PEIE resulted in the formation of a thin interfacial dipole between the active layer and the ETL. Also, composite materials based on semiconductor material (e.g. zinc oxide $^{118}$ and titanium dioxide ${ }^{119}$ ) with PEI or PEIE can act as the buffer cathode (i.e. ETL) $)^{120,121}$ or as a protective layer in a hybrid organic-inorganic photocathode for hydrogen evolution operated in acidic conditions. ${ }^{122}$

Regarding the structure of inverted polymer solar cells, the interfacial layer is placed between the active layer material (e.g. fullerenes and conjugated polyelectrolytes (CPEs)) and the cathode (e.g. ITO). In the study of Jia et al., ${ }^{123}$ the ETL based on zinc oxide and PEI combined the advantages of both semiconductor and polymer components responsible for high charge carrier mobility and good film formation ability, respectively. The authors demonstrated that blending of PEI within the oxide film improved the surface roughness of the zinc oxide film, enhanced the structural order of zinc oxide in zinc oxide:PEI composite perpendicular to the surface of ITO the cathode and, consequently, significantly increased the mobility of electrons in the vertical direction with the content of PEI in the composite film up to $7 \mathrm{wt} \%$. The use of zinc oxide-PEI composite in inverted solar and perovskite solar cells showed an improvement in power conversion efficiency (PCE) in comparison with the cases wherein only zinc oxide and PEI are used as cathode buffer layers. ${ }^{123}$ In addition, the device stability (in comparison with the stability of the control device without the cathode buffer layer zinc oxide:PEI) also increased.

One of the ways to increase the PCE value is to employ multijunction solar cells instead of single-junction ones. However, the main obstacle for the arising applications of such devices is interfacial losses between the hole-transporting layer (HTL) (e.g. poly(3,4-ethylenedioxythiophene) (PEDOT):PSS or molybdenum oxide nanoparticles) and the active polymer layers. Du et al. ${ }^{124}$ showed that a multilayer consisting of HTL-zinc oxide-PEI possesses all the requirements needed for efficient intermediate layers in multijunction solar cells - high charge carrier recombination efficiency, high transparency and high physical robustness. In addition, tandem solar cells with this intermediate layer showed nearly no loss of $V_{\mathrm{oc}}$ and a function comparable to that of reference single-junction solar cells.

The deposition of PEI directly onto the surface of semiconductor films leads to the smoothening of the surface, decreasing the $R_{\mathrm{ms}}$ value. For the applications in solar cells, this fact can play an important role in the improvement of charge transfer. For example, the smooth interface morphology of a hybrid titanium dioxide-PEI film ${ }^{91}$ can reduce interfacial defects of the semiconductor film followed by diminished light scattering and reflection. Additionally, a reduction in the recombination of charge carriers after polyelectrolyte deposition can also result from the smooth and featureless interface morphology. The magnification of the device short-circuit density $J_{\mathrm{sc}}$ is the consequence of titanium dioxide-PEI's positive effect on device performance in comparison with a pure titanium dioxide layer. Recombination dynamics and charge transport were measured using EIS (Figure 4(f)). The curve in the low-frequency region depends on the charge transport between the active layer and ITO electrode. Devices based on a PEI-modified titanium dioxide layer possess low charge transfer resistance in comparison with the pristine titanium dioxide-based device, demonstrating the probable facilitation of the electron transport from the ITO cathode to the active polymer-based layer and decreasing contact resistance. ${ }^{125}$ The $J-V$ measurements under dark conditions confirmed the suggestion of the electron transport enhancement in the case of titanium dioxide-PEI-modified solar cells.

Yan et al. ${ }^{126}$ studied the effect of PEI layer deposition onto a titanium dioxide ETL on the device behavior. The authors altered the deposition of the polyelectrolyte on the top of the semiconductor coating, underneath it or in the bulk. It has been demonstrated that PEI deposition on the top of the titanium dioxide ETL facilitated the extraction of photogenerated electrons due to the formation of strong dipoles formed at the active layer-ETL interface, reduced energy barrier and, consequently, stabilized maximized efficiency. The maximum PCE value of the titanium dioxide-PEI-based device was c. 10\%, whereas for pure titanium dioxide, the value was c. $9 \cdot 5 \%$. In another experiment, the authors blended titanium dioxide nanoparticles directly with PEI solution to obtain bulky functionalized titanium dioxide coating and estimated the impact on the performance of the solar cell. The optimal content of PEI turned out to be $10 \mathrm{wt} \%$, which facilitated the dispersion and stabilization of titanium dioxide nanoparticles. With the use of lower or higher amounts of PEI, large aggregates of the semiconductor nanoparticles on the substrate were observed. Thus, the optimal concentration of PEI 
can lead to the formation to the cluster-free films, and, as a result, the highest PCE value is related to the optimal conditions of light absorption. The deposition of PEI underneath the titanium dioxide layer decreased the work function of the ITO (from 4.62 to $3.97 \mathrm{eV}$ ), facilitating charge extraction. Moreover, the softness of the polyelectrolyte in a viscous state permits penetration into the oxide layer, reducing its work function and reaching the highest efficiency. The preparation of the PEI-titanium dioxide-PEI triple layer where the polyelectrolyte was deposited both underneath and on the top of the titanium dioxide layer resulted in the reduction of $J_{\mathrm{sc}}$ and $V_{\mathrm{oc}}$ values - the authors suggest such reduction of the device parameters with the inhibiting nature of multiple PEI layers followed by hampering of electron transport.

Addition of a negatively charged polyelectrolyte - for example, PSS, ${ }^{127}$ which supplies counter ions for positively charged PEI and, consequently, the formation of an polyelectrolyte complex can lead to the tuning of the cathode work function, enhancement of the photocurrent and the device PCE value, resulting from the enhanced electron extraction at the PEI:PSS-active layer interface. The use of a titanium oxide (TiOx)-PEI:PSS bilayer system as an interfacial layer showed a decrease in series resistance, lowering the work function of the TiOx layer thus eliminating the energy barriers for electron transport and injection.

A special class of polyelectrolytes - CPEs - is interesting for solar cell applications as sensitizers due to their good absorption properties, adjustable bandgap and charge and exciton transport properties. ${ }^{128,129} \mathrm{CPEs}$ are $\pi$-conjugated polymers with ionic or ionizable groups on a $\pi$-conjugated backbone ${ }^{130}$ and can be used as a light-harvesting material in DSSCs. Studies of CPE absorption onto the surface of semiconductor single crystals were performed in several works. ${ }^{12-131}$ The nearly atomically flat surfaces of zinc oxide and titanium dioxide single crystals were used as model systems for the investigation of the CPE adsorption behavior. The proper choice of solvent, exposure time and concentration led to the necessary polymer chain length, surface coverage and thickness of the resulted film. The resulted polymer coating possesses the appropriate light absorption and electron injection properties for obtaining the incident photon-to-current and absorbed photon-to-current efficiency values adapted for further solar cell fabrication. ${ }^{131}$ Zhu et al. ${ }^{129}$ provided the conditions for avoiding aggregation of CPE molecules in the solution and after the adsorption on zinc oxide surface. The polyelectrolyte molecules were present as single unaggregated chains with a coiled conformation consisting of a helical structure, stabilized by $\pi$-interactions and hydrogen bonds between the carboxylic groups. This was confirmed by atomic force microscopy analysis. The unaggregated CPEs underwent efficient charge injection into the oxide semiconductor.

Fluorine-based CPEs as investigated by Pan et al. ${ }^{130}$ produce interlayers with high transparency and smooth surface morphology with the decrease in the work function of a zinc oxide-coated ITO electrode. An ultrathin layer of CPE $(\sim 5 \mathrm{~nm})$ leads to the suppression of the charge carrier recombination and series resistance. The double interlayer zinc oxide-CPE structure allows preparation of high-performance organic PV devices.

In summary, the functionalization of the intermediate ETL of zinc oxide or titanium dioxide by polyelectrolyte layers can lead to the improvement in the performance of solar cell devices in comparison with non-modified zinc oxide and titanium dioxide analogs. Such hybrid structure can combine the advantages of both components - high electron affinity, transparency, air stability from one side and the ability of thin film formation from the other. The introduction of polyelectrolytes leads to the elimination of poor contacts on the ETL-active layer interfaces caused by the intrinsic surface defects of the inorganic semiconductor. Polyelectrolytes facilitate charge transport through the formation of dipole moments on the interface. Also, the degree of functional group ionization can lead to changes in charge carrier transport characteristics. Moreover, the important feature for the enhancement of the device performance is the formation of non-aggregated polyelectrolyte coating in order to obtain the maximum light absorbance and photoelectrochemical characteristics. That is why the precise control of film thickness and degree of polyelectrolyte aggregation is very important during the procedure of polyelectrolyte layer deposition or incorporation into the inorganic layer. The aforementioned factors open perspectives on the fabrication of high-performance solar cells or organic PVs based on the intermediate hybrid semiconductor-polyelectrolyte layer.

\subsection{Self-regulated processes}

Among trends in the design of smart materials, self-regulated materials and processes at interfaces play an important role, and the following aspects are under consideration: $(a)$ the choice of the proper material and its environment; $(b)$ stability of the material to the degradation under different environmental conditions; (c) mechanism of the degradation; $(d)$ strategies for improvement of the material properties (e.g. stability); and (e) an attempt to make materials self-responsive during degradation. In this review, the authors discuss self-healing and self-cleaning materials and their autocatalytic network design.

Self-healing materials are a class of advanced materials that have the ability to control feedback processes, for example, at the solid-polyelectrolyte interface. ${ }^{132}$ First, the nature of changes near the solid surface and in the local environment is important - for example, a change in $\mathrm{pH}$ during the corrosion process. ${ }^{133}$ Second, it is important to find proper polyelectrolytes that could be responsible for stabilization ('healing') of the inorganic component damaged by the change in the surrounding medium. In this case, weak polyelectrolytes that are sensitive to $\mathrm{pH}$ alteration and can exhibit buffer properties (e.g. chitosan and PEI as representatives of the imine class) could be mentioned. ${ }^{134}$ The composition of the PEMs should be also regarded. For instance, the $\mathrm{LbL}$ approach can be used for optimizing the architecture of the layers for providing both the 
effect of $\mathrm{pH}$ buffering and improved material stability. ${ }^{135}$ Selfhealing has a broad spectrum of applications, including corrosion protection, ${ }^{132-137}$ elements of antifouling and antimicrobial coatings ${ }^{138}$ and bioinspired superhydrophobic interfaces. ${ }^{139}$

The self-healing of metals by polyelectrolyte assemblies is associated with several factors ${ }^{132-140}$ (Figure 9): (a) pH normalization through weak polyelectrolyte buffering; $(b)$ the polyelectrolyte chain waterinduced mobility; and $(c)$ the possibility of release of organic molecules (healing agents). The versatile technology for the formation of self-regulated corrosion systems can be extended and optimized for novel trends and future needs. ${ }^{132}$

Today a particular research interest is paid to the area of systems that convert an input signal into a single output in a non-linear way. ${ }^{141}$ From the chemical point of view, the oscillation reactions convert a steady supply of reactants into a periodic production of products. From the signal process point of view, one of the reactants is an input signal and one of the products is an output (Figure 10). ${ }^{50,60-63}$ The oscillatory network first transits from steady output to oscillatory output and then back to a steady state. The presented oscillator in Figure 10 uses trypsinogen (zymogen of the proteolytic enzyme trypsin), a synthetic tripeptide (a masked inhibitor for trypsin) and aminopeptidase (another proteolytic enzyme) as source materials. Oscillations result from the interaction between a positive feedback loop, which consists of an autocatalytic production of trypsin from trypsinogen, and a delayed negative feedback loop, which consists of trypsin inhibitor production. Interestingly, it was shown that titania-polyelectrolyte particles can drastically affect the network and propagation of the autocatalytic wave on the surface. ${ }^{50}$ The challenges in this area include $(a)$ predictive design of the interface chemical switches and oscillators and $(b)$ computing cascades with bacterial signaling and metabolism.

In the field of model self-cleaning materials, antifouling coatings $^{139}$ and model microbiome systems ${ }^{142,143}$ should be also mentioned. The effects of antibacterial evaluation suggest that the nanofunctionalized titanium dioxide coating possesses excellent antimicrobial activity. ${ }^{142}$ An interdisciplinary approach includes the complementary experience in the development of PMs able to communicate with bacterial biofilms.

Can the behavior of bacterial communities (B) be manipulated by programming photoreactions on the surface of well-studied materials - for example, nanoengineered semiconductor composite
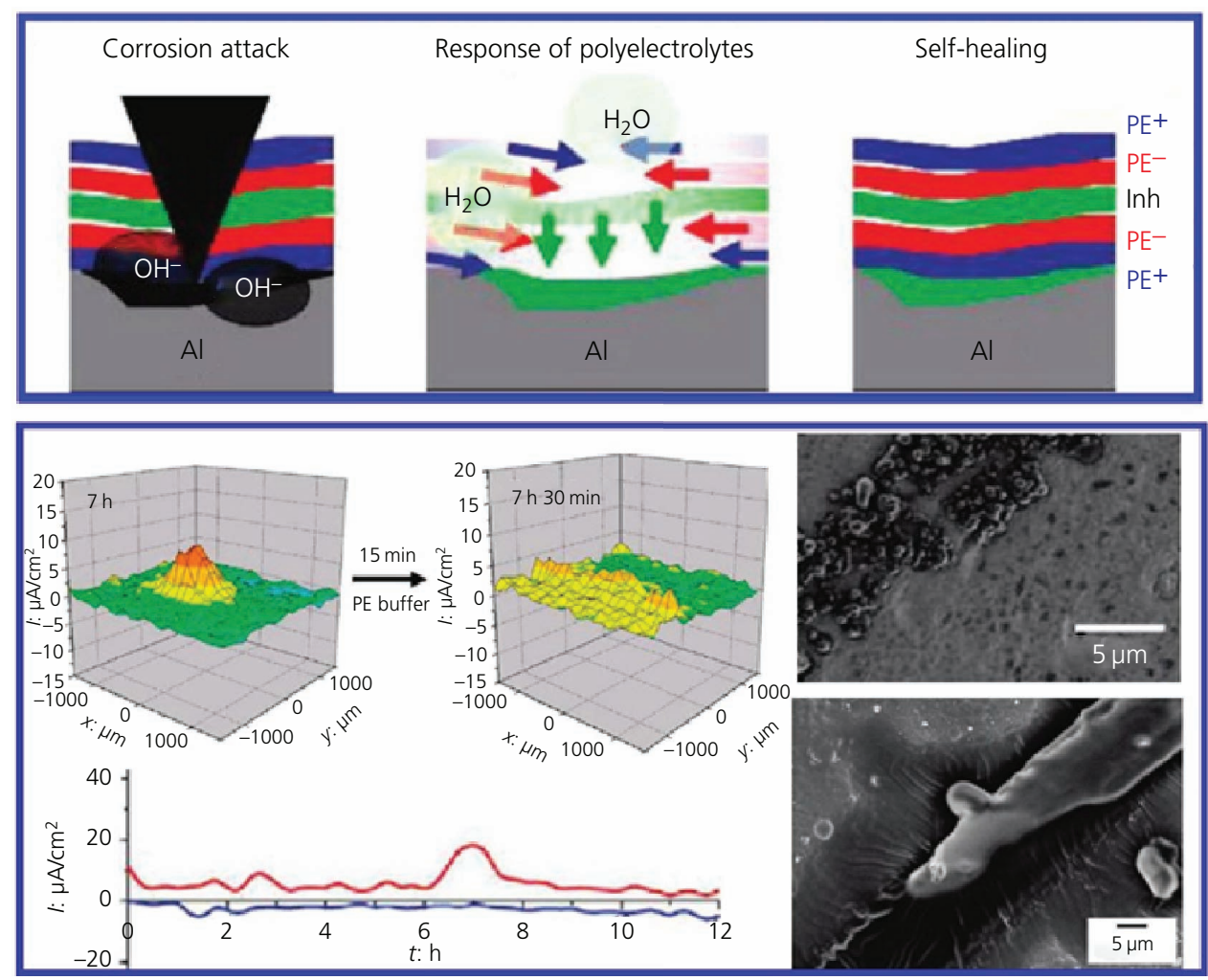

Figure 9. Corrosion zone self-healing mechanism based on LbL assembly of polyelectrolyte (PE): schematic diagram of corrosion attack with a change in $\mathrm{pH}$ and immediate response of polyelectrolytes with corrosion inhibitor in composition (Inh); corresponding SVET maps and graphs of minimum and maximum cathodic and anodic activities proving self-healing; scanning electron microscopy images of a corroded defect and progress of the healing of the defect with polyelectrolytes. Adapted from Andreeva et al. ${ }^{135}$ 


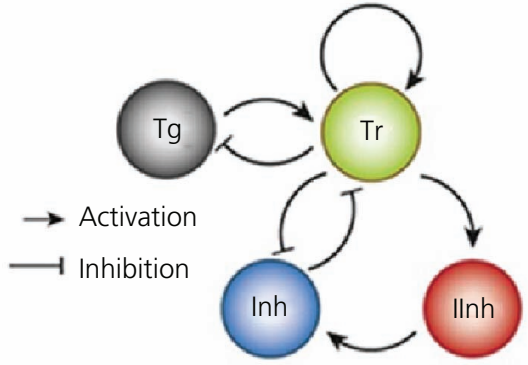

(a)

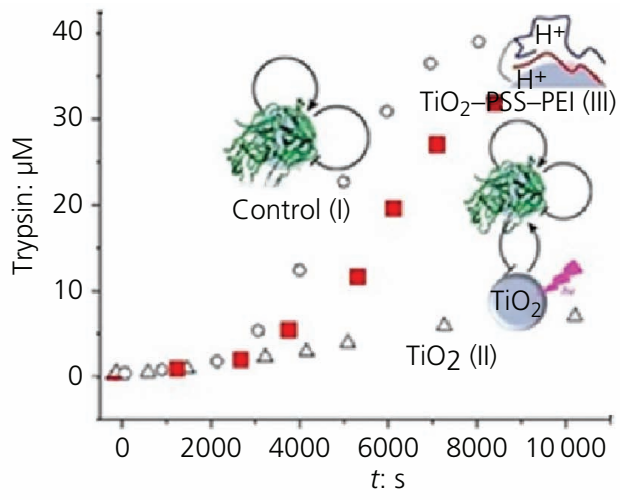

(c)
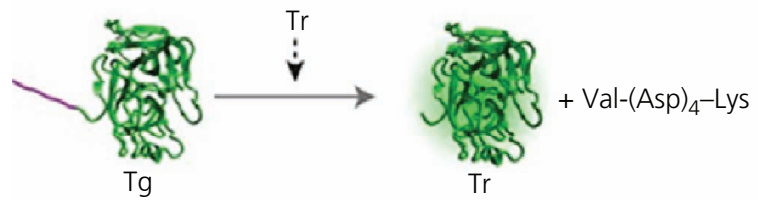<smiles>C[NH2+]CCCC[C@H](NC(C)=O)C(=O)NC(CCC(N)=O)C(=O)NCCc1ccc(S(=O)(=O)F)cc1</smiles>

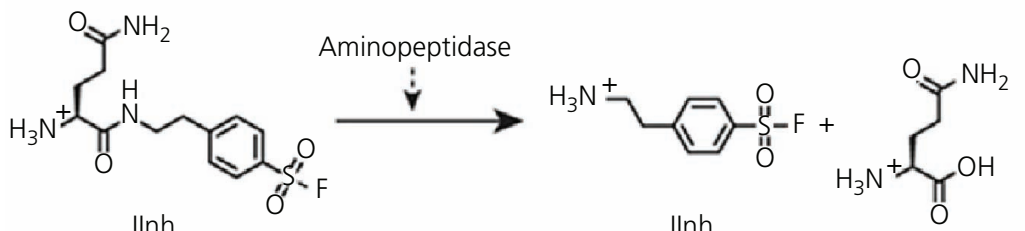

IInh

IInh

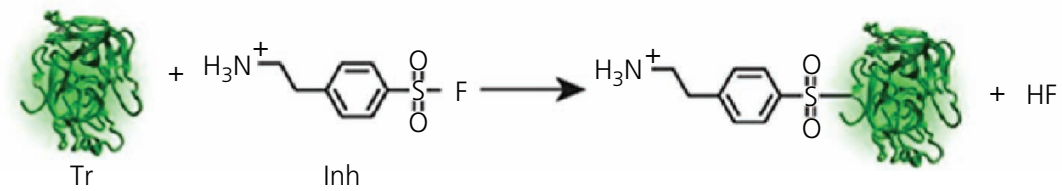

(b)

Figure 10. Autocatalytic trypsin (Tr) oscillator. (a) Depiction of the network of enzymatic reactions in the trypsin oscillator. (b) Specific reactions in the reaction network. Dashed arrows indicate catalysis. Reprinted with permission from Semenov et al. ${ }^{61}$ (c) Inclusion of additional components into the trypsin oscillator drastically changes its kinetics: conversion of the fluorogenic substrate monitored at $\lambda_{\mathrm{ex}}=450 \mathrm{~nm}$ and $\lambda_{\mathrm{em}}=520 \mathrm{~nm}$; each point is checked for $60 \mathrm{~s}$ with a time interval of $1 \mathrm{~s}$. I, trypsin control reaction; II, III, reaction in the presence of titanium dioxide (II) or titanium dioxide-PSS-PEI (III) under irradiation. Reprinted with permission from Lanchuk et al. ${ }^{50}$ IInh, intermediate inhibitor; Inh, inhibitor; Plnh, proinhibitor; Tg, trypsinogen

surfaces (PM) (Figure 11(a))? If a bacteria/biofilm binary system can be regarded as a single unit (B), where bioreactions may activate or inhibit bacterial metabolism (Figure 11(b)), programming temporal reactions can be taken under consideration. Communication between bacteria of a given type by means of specific chemical species is becoming a rising topic of research, ${ }^{14-151}$ Ion channels enable electrical communication within bacterial communities ${ }^{144}$ (Figure 11(c)). Different types of bacteria communicate within biofilms ${ }^{145}$ (Figure 11(d)). Thus, it should be possible to make them follow a given spatiotemporal program dictated by a photoresponsive material (Figure 11(e)).
Recently, Prindle et al. ${ }^{144}$ have studied in detail the temporal synchronization and desynchronization of biofilm behavior (Figure 11(b)) in response to oscillations in potassium $\left(\mathrm{K}^{+}\right)$ion concentration. However, there was not any study that could propose spatial localization of the programming signal in systems containing synthetic ionic channels. Ulasevich et al. $^{71}$ in their work aimed to fill this gap with photosensitive materials capable of locally controlled release of hydrogen and potassium ions with a further study of the resulting changes in biofilm growth and cell response. ${ }^{70}$ Reversible oscillation of LbL films based on high-amplitude actuation of BCMs allows controlling the 


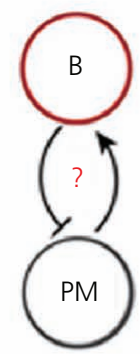

(a)

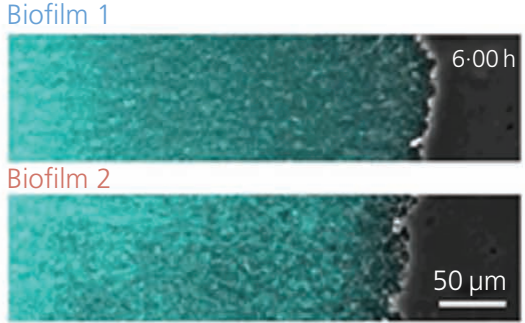

Public goods

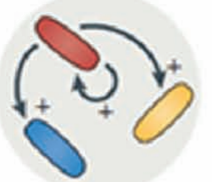

(d)

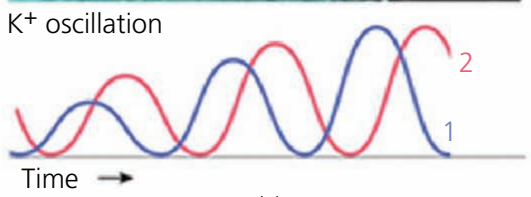

(c)

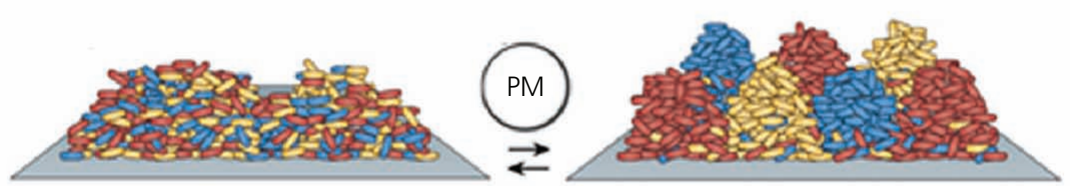

(e)

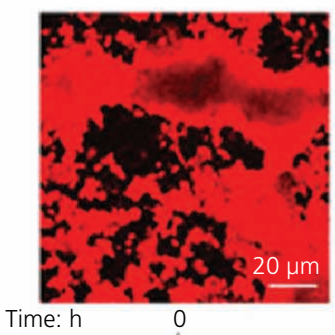

Time: $h$
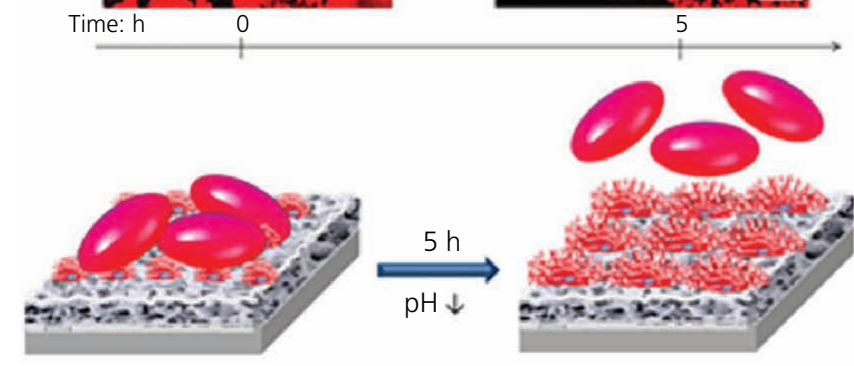

(f)
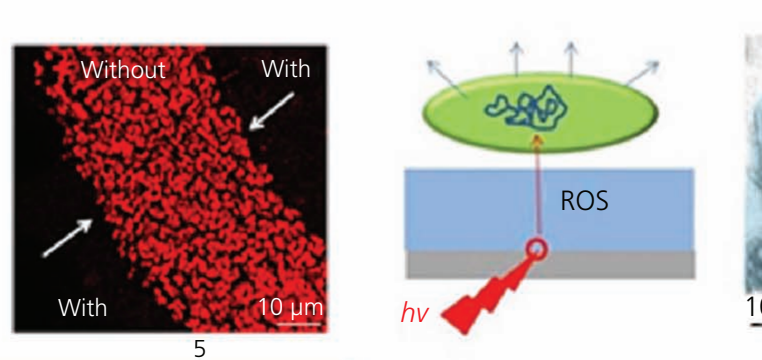

(g)

Figure 11. Taking microbial metabolism as part of a complex system for switching feedback stimuli between PMs and materials. (a) How to program bacterial communities is a key point in the authors' project. (b) A bacterial community has its own feedback mechanism - for example, (c) oscillation of potassium ions in time depending on chemical surroundings, (d) spatial structure, co-operation and competition in biofilms of different bacterial communities (shown in red, blue and yellow) to be programmed on the nanoengineered surface - for example, by photocontrolled local reactions. (c) is adapted from Prindle et al., ${ }^{144}$ and (d) and (e) are adapted from Rivera-Chavez and Bäumler. ${ }^{145}$ ( $\mathrm{f}$ ) Self-controllable system. Confocal kinetic study (fluorescence mode) and schematic illustration of pH-triggered self-cleaning behavior of a porous metal surface covered with pH-responsive micelles. Lactococcus lactis 411 bacteria (loaded with dye) were used as model cells. Bacteria decrease the $\mathrm{pH}$; micelles respond to the change and increase in size; and bacteria detach from the surface, remaining just on the surface without micelles. Adapted from Gensel et al. ${ }^{146}(\mathrm{~g})$ Schematic representations of a photoactuator employing photogeneration of ROS to alter cell metabolism (inducing apoptosis and proliferation or production of certain metabolites). Transmission electron microscopy image demonstrating the effect of ROS generated at titanium dioxide on the metabolism of lysogenic $L$. lactis bacteria (i.e. containing bacteriophage genes in their DNA). The opening of the cell envelope and the release of viruses is observed. Adapted from Skorb et al. ${ }^{147}$

cell behavior on the surface. Ulasevich et $a l .^{71}$ have successfully applied switching of a polyelectrolyte assembly by light to control the behavior of supported cells. ${ }^{70}$ In particular, the change in stiffness results in migration of cells to a harder surface.
A systematic study of nanoscale surface design is needed to program significant bioresponses. $\mathrm{BCM}$ polyelectrolyte brushes adsorbed on mesoporous surface demonstrated ${ }^{146}$ an affective self-cleaning property of lactic bacteria. Lactic bacteria 
produced lactic acid and activated BCMs - the polymer coating increased in its thickness and pushed the bacteria out of the surface. Bassler's ${ }^{148}$ paper focuses on the synergy between PMs and living bacteria that can be deactivated; however, more interestingly, bacteria survive and interact with PMs in a predictive way. Lactic bacteria could reversibly be activated/ deactivated by PMs due to the cyclic metabolic process in their life cycle.

Nowadays two important features, (a) bacterial metabolism regulation and stimulation and $(b)$ degradation of bacteria due to a lethal concentration of reactive oxygen species (ROS), are being intensively discussed. The ROS photogenerated on titania could further penetrate into the intracellular volume and alter the activity of the microorganisms. Both photokilling of bacteria and profound changes in their metabolism can be attained depending on the exposure used: the authors are interested in changing the metabolism without deactivation of bacteria. In the authors' previous work, it has been shown ${ }^{147}$ (Figure 11(g)) that ROS produced on titania surface effectively induce lytic cycles of lysogenic bacteria without killing them. To enhance the superoxide yield and bacteria adhesion, bimetallic silver-nickel nanoparticles can be deposited in the pores of a titania film. ${ }^{51}$ The main objective in this field of research is to develop PMs which interact with bacteria growing on the materials, opening the questions of (a) what type of chemistry is suitable for communication with bacteria; (b) how to design two-sided communication - that is, processing of signals coming from both the bacterial signaling network and synthetic chemical network; and $(c)$ how can synthetic chemistry influences and responds to bacterial activity.

\section{Conclusions}

In this paper, several aspects of the inorganic (semiconductor or metal)-PEM interface usability are highlighted. Processes at interfaces are important for multiple-stimulus-responsive materials ('photon-to-proton conversion', where electromagnetic irradiation leads to the formation of photogenerated protons and thus a decrease in the $\mathrm{pH}$ value of the subsurface layer of the irradiated material). External stimuli can be regarded as triggers for the actuation of soft matter without its destruction. Polyelectrolyte deposition can impact differently on the photocatalytic activity of the hybrids - in some cases, polyelectrolytes and semiconductors can have a synergistic effect of photocatalytic activity enhancement, and, in the others, polymer coatings can suppress the photoactivity of the inorganic component. In general, the functionalization of the interfacial layers with polyelectrolytes in solar cells leads to the enhancement of the device performance due to the improved light absorption and enhanced electron transport from the active layer to the device. The aforementioned characteristics of the hybrids provide possibilities of their exploitation in various applications. Self-regulated systems are discussed together with the existing problems of interdisciplinary view to the problem of design of PMs 'living' together with biological networks.

\section{Acknowledgements}

This work was supported by the Russian Foundation for Basic Research under research project number 18-38-20182.

\section{REFERENCES}

1. Xiang B, Li Y, Huy Pham C, Paesani F and Xiong W (2017) Ultrafast direct electron transfer at organic semiconductor and metal interfaces. Science 3(11): e1701508.

2. Zhang H, Guo X, Hui J et al. (2011) Interface engineering of semiconductor/dielectric heterojunctions toward functional organic thin-film transistors. Nano Letters 11(11): 4939-4946.

3. Bradley DDC (1991) Characterization of polymers for semiconductor applications. Polymer International 26(1): 3-16.

4. Skorb EV and Andreeva DV (2014) Layer-by-layer smart coatings for corrosion protection. In Handbook of Smart Coatings for Corrosion Protection (Hamdy AS (ed.)). Woodhead Publishing, Cambridge, UK, vol. 64, pp. 307-327.

5. Supplie O, May MM, Brückner S et al. (2017) In situ characterization of interfaces relevant for efficient photo-induced reactions. Advanced Materials Interfaces 4(21): 1601118.

6. Delcea M, Möhwald H and Skirtach AG (2011) Stimuli-responsive LbL capsules and nanoshells for drug delivery. Advanced Drug Delivery Reviews 63(9): 730-747.

7. Whitesides GM and Grzybowski B (2002) Self-assembly at all scales. Science 295(5564): 2418-2421.

8. Skorb EV, Skirtach A, Sviridov DV, Shchukin DG and Möhwald H (2009) 'Smart' laser-controllable coatings for corrosion protection. ACS Nano 3(7): 1753-1760.

9. Garmire E (1994) Nonlinear optics in semiconductors. Physics Today, May: pp. 42-48.

10. Walker BT, Flatten LC, Hesten HJ et al. (2018) Driven-dissipative non-equilibrium Bose-Einstein condensation of less than ten photons. Nature Physics 14: 1173-1177.

11. Ropp C, Bachelard N, Barth D, Wang Y and Zhang X (2018) Dissipative self-organization in optical space. Nature Photonics 12(12): 739-743.

12. Lonergan MC (1997) A diode tunable based on an inorganic semiconductor/conjugated polymer interface. Science 278(5346): 2103-2106.

13. Skorb EV, Shchukin DG and Sviridov DV (2008) Hybrid silica-zirconia films loaded with titania nanoparticles and titaniabased nanocontainers: novel materials for thin-film photocatalysts and photocontrollable coatings. In Molecular and Nanoscale Systems for Energy Conversion (Varfolomeev S (ed.)). Nova Science Publishers, New York, NY, USA, pp. 75-87.

14. Shchukin DG, Andreeva DV, Skorb EV and Möhwald H (2010) Emerging concepts in interfacial chemistry of hybrid materials. In Supramolecular Chemistry of Hybrid Materials (Rurack K (ed.)). Wiley-VCH, Weinheim, Germany, pp. 639-653.

15. Mamidala V, Nalla V, Maiti PS, Valiyaveettil and Ji W (2013) Charge transfer assisted nonlinear optical and photoconductive properties of $\mathrm{CdS}-\mathrm{AgInS} \mathrm{S}_{2}$ nanocrystals grown in semiconducting polymers. Journal of Applied Physics 113(12): 123107.

16. Pan C, Dong L, Ge L, Wang J and Gu Z (2009) Highly active $\mathrm{TiO}_{2} /$ polyelectrolytes hybrid multilayered hollow nanofibrous photocatalyst prepared from electrospun fibers using electrostatic layer-by-layer technique. Journal of Macromolecular Science, Part B: Physics 48(1): 92-105.

17. Shchukin DG and Sviridov DV (2006) Photocatalytic processes in spatially confined nanoreactors. Journal of Photochemistry and Photobiology C: Photochemistry Reviews 7(1): 23-29.

18. Shchukin DG, Ustinovich EA, Sukhorukov GB, Möhwald $H$ and Sviridov DV (2005) Metallized polyelectrolyte microcapsules. Advanced Materials 17(4): 468-472.

19. Sun $S$, Deng $T$, Ding $H$, Chen $Y$ and Chen W (2017) Preparation of nano- $\mathrm{TiO}_{2}$-coated $\mathrm{SiO}_{2}$ microsphere composite material 
and evaluation of its self-cleaning property. Nanomaterials 7(11): 367

20. Shchukin DG and Sukhorukov GB (2004) Nanoparticle synthesis in engineered organic nanoscale reactors. Advanced Materials 16(8): 671-682.

21. Carre G, Garnier L, Moeller-Sigert J et al. (2015) Antibacterial textiles functionalized by layer-by-layer assembly of polyelectrolytes and $\mathrm{TiO}_{2}$ photocatalyst. RSC Advances 5(49): 38859-38867.

22. Dal'Acqua N, Scheffer FR, Boniatti R et al. (2013) Photocatalytic nanostructured self-assembled poly(allylamine hydrochloride)/poly (acrylic acid) polyelectrolyte films containing titanium dioxide-gold nanoparticles for hydrogen generation. Journal of Physical Chemistry C 117(44): 23235-23243.

23. Faria ACR, Vebber MC, Dal'Acqua N et al. (2017) Characterization and application of self-assembled thin films of polyelectrolyte/ $/ \mathrm{TiO}_{2} /$ $\mathrm{CdSe}$ for hydrogen production. International Journal of Hydrogen Energy 42(26): 16568-16578.

24. Shchukin DG, Ustinovich EA, Sviridov DV, Lvov YM and Sukhorukov GB (2003) Photocatalytic microreactors based on $\mathrm{TiO}_{2}$-modified polyelectrolyte multilayer capsules. Photochemical \& Photobiological Sciences 2(10): 975-977.

25. Zhu H, Jiang $\mathrm{R}$, Xiao L et al. (2013) CdS nanocrystals/ $/ \mathrm{TiO}_{2} /$ crosslinked chitosan composite: facile preparation, characterization and adsorption-photocatalytic properties. Applied Surface Science 273: 661-669.

26. Timin AS, Muslimov AR, Lepik KV et al. (2016) Triple-responsive inorganic-organic hybrid microcapsules as a biocompatible smart platform for the delivery of small molecules. Journal of Materials Chemistry B 4(45): 7270-7282.

27. Gao H, Wen D, Tarakina NV et al. (2016) Bifunctional ultraviolet/ ultrasound responsive composite $\mathrm{TiO}_{2}$ /polyelectrolyte microcapsules. Nanoscale 8(9): 5170-5180.

28. Bang K, Lim H, Park S and Suh K (2015) A facile template-free synthesis of $\mathrm{pH}$-responsive polyelectrolyte/amorphous $\mathrm{TiO}_{2}$ composite hollow microcapsules for photocatalysis. RSC Advances 5(73): 59257-59262.

29. Essawy AA, Sayyah SM and El-Nggar AM (2017) Wastewater remediation by $\mathrm{TiO}_{2}$-impregnated chitosan nano-grafts exhibited dual functionality: high adsorptivity and solar-assisted self-cleaning. Journal of Photochemistry and Photobiology B: Biology 173: 170-180.

30. Vebber MC, Faria ACR, Dal'Acqua N et al. (2016) Hydrogen production by photocatalytic water splitting using pol(allylamine hydrochloride)/poly(acrylic acid)/ $\mathrm{TiO}_{2} /$ copper chlorophyllin selfassembled thin films. International Journal of Hydrogen Energy 41(40): 17995-18004.

31. Xiao G, Su H and Tan T (2015) Synthesis of core-shell bioaffinity chitosan- $\mathrm{TiO}_{2}$ composite and its environmental applications. Journal of Hazardous Materials 283: 888-896.

32. Renfigo-Herrera JA, Marin-Silva DA, Mendoza-Portillo E, Pinotti AN and Pizzio (2018) Chitosan films containing $\mathrm{TiO}_{2}$ nanoparticles modified with tungstophosphoric acid for the photobleaching of malachite green in solid-gas interfaces upon different wavelengths. Molecular Catalysis 448: 1-9.

33. Yang YH, Ren N, Zhang YH and Tang Y (2009) Nanosized cadmium sulfide in polyelectrolyte protected mesoporous sphere: a stable and regeneratable photocatalyst for visible-light-induced removal of organic pollutants. Journal of Photochemistry and Photobiology A: Chemistry 201(2-3): 111-120.

34. Pincus LN, Melnikov F, Yamani JS and Zimmerman JB (2018) Multifunctional photoactive and selective adsorbent for arsenite and arsenate: evaluation of nano titanium dioxide-enabled chitosan crosslinked with copper. Journal of Hazardous Materials 358(15): 145-154.

35. Neela Priya D, Modak JM and Raichur AM (2009) LbL fabricated poly(styrenesulfonate) $/ \mathrm{TiO}_{2}$ multilayer thin films for environmental applications. ACS Applied Materials \& Interfaces 1(11): 2684-2693.
36. Fares HM and Schlenoff JB (2017) Diffusion of sites versus polymers in polyelectrolyte complexes and multilayers. Journal of the American Chemical Society 139(41): 14656-14667.

37. Fares HM, Ghoussoub YE, Surmaitis RL and Schlenoff JB (2015) Toward ion-free polyelectrolyte multilayers: cyclic salt annealing. Langmuir 31(21): 5787-5795.

38. Schlenoff JB (2018) Site-specific perspective on interactions in polyelectrolyte complexes: toward quantitative understanding. Journal of Chemical Physics 149(16): 163314

39. Delgado JD and Schlenoff JB (2017) Static and dynamic solution behavior of a polyzwitterion using a Hofmeister salt series. Macromolecules 50(11): 4454-4464.

40. Suzurikawa J, Nakao M, Kanzaki R and Takahashi H (2010) Microscale $\mathrm{pH}$ gradient generation by electrolysis on a lightaddressable planar electrode. Sensors and Actuators 149(1): 205-211.

41. Cheng Y, Yang QD, Xiao J et al. (2015) Decomposition of organometal halide perovskite films on zinc oxide nanoparticles. ACS Applied Materials \& Interfaces 7(36): 19986-19993.

42. Maltanava HM, Poznyak SK, Andreeva DV et al. (2017) Lightinduced proton pumping with a semiconductor: vision for photoproton lateral separation and robust manipulation. ACS Applied Materials \& Interfaces 9(28): 24282-24289.

43. Andreeva DV, Kollath A, Brezhneva N et al. (2017) Using a chitosan nanolayer as an efficient buffer to protect $\mathrm{pH}$-sensitive supramolecular assemblies. Physical Chemistry Chemical Physics 19(35): 23843-23848

44. Brezhneva N, Nikitina A, Ryzhkov N et al. (2019) Importance of buffering nanolayer position in layer-by-layer assembly on titania based hybrid photoactivity. Journal of Sol-Gel Science and Technology 89(1): 92-100.

45. Schouten C, van den Beucken JJ, de Jonge LT et al. (2009) The effect of alkaline phosphatase coated onto titanium alloys on bone responses in rats. Biomaterials 30(32): 6407-6417.

46. Muderrisoglu C, Saveleva M, Abalymov A et al. (2018) Nanostructured biointerfaces based on bioceramic calcium carbonate/hydrogel coatings on titanium with an active enzyme for stimulating osteoblasts growth. Advanced Materials Interfaces 5(19): 1800452

47. Li Z, Zhang X, Liu C et al. (2016) Enhanced electron extraction capability of polymer solar cells via employing electrostatically selfassembled molecule on cathode interfacial. ACS Applied Materials \& Interfaces 8(12): 8224-8231.

48. Fusco C, Casiello M, Catucci L et al. (2018) TiO 2 @PEI-graftedMWCNTs hybrids nanocomposites catalysts for $\mathrm{CO}_{2}$ photoreduction. Materials 11(2): 307

49. Vallejo-Montesinos J, Martinez JCL, Montejano-Carrizales JM et al. (2017) Passivation of titanium oxide in polyethylene matrices using polyelectrolytes as titanium dioxide surface coatings. Mechanics, Materials Science \& Engineering 8: 38-50.

50. Lanchuk Y, Nikitina A, Brezhneva N et al. (2018) Photocatalytic regulation of an autocatalytic wave of spatially propagating enzymatic reactions. ChemCatChem 10(8): 1798-1803.

51. Skorb EV and Möhwald H (2013) Dynamic interfaces for responsive encapsulation systems. Advanced Materials 25(36): 5029-5043.

52. Skorb EV and Möhwald H (2014) 'Smart' surface capsules for delivery devices. Advanced Materials Interfaces 1(6): 1400237.

53. Skorb EV, Volkova A and Andreeva DV (2014) Layer-by-layer assembled hybrid materials for sustainable applications. Current Organic Chemistry 18(18): 2315-2333.

54. Skorb EV, Volkova A and Andreeva DV (2015) Layer-by-layer approach for design of chemical sensors and biosensors. Current Organic Chemistry 19(12): 1097-1116.

55. Skorb EV and Andreeva DV (2015) Self-healing properties of layer-by-layer assembled multilayers. Polymer International 64(6): $713-723$. 
56. Skorb EV and Andreeva DV (2013) Bio-inspired ultrasound assisted construction of synthetic sponges. Journal of Materials Chemistry A 1(26): $7547-7557$

57. Skorb EV, Shchukin DG, Möhwald H and Sviridov DV (2009) Photocatalytically-active and photocontrollable coatings based on titania-loaded hybrid sol-gel films. Journal of Materials Chemistry 19(28): 4931-4937.

58. Wu F, Su RQ, Lai YC and Wang X (2017) Engineering of a synthetic quadrastable gene network to approach Waddington landscape and cell fate determination. eLife 6: e23702.

59. Nikitina AA, Ulasevich SA, Kassirov IS et al. (2018) Nanostructured layer-by-layer polyelectrolyte containers to switch biofilm fluorescence. Bioconjugate Chemistry 29(11): 3793-3799.

60. Semenov SN, Wong ASY, van der Made AM et al. (2015) Rational design of functional and tunable oscillating enzymatic networks. Nature Chemistry 7(2): 160-165.

61. Semenov SN, Ainla A, Skorb EV and Postma S (2018) Four-variable model of an enzymatic oscillator based on trypsin. Israel Journal of Chemistry 58(6-7): 781-786.

62. Pogodaev AA, Wong ASY and Huck WTS (2017) Photochemical control over oscillations in chemical reaction networks. Journal of the American Chemical Society 139(43): 15296-15299.

63. Wong ASY and Huck WTS (2017) Grip on complexity in chemical reaction networks. Beilstein Journal of Organic Chemistry 13(1): 1486-1497.

64. Sirasani G, Tong LC and Balskus EP (2014) A biocompatible alkene hydrogenation merges organic synthesis with microbial metabolism. Angewandte Chemie International Edition 53(30): 7785-7788.

65. Wallace S, Schultz EE and Balskus EP (2015) Using non-enzymatic chemistry to influence microbial metabolism. Current Opinion in Chemical Biology 25: 71-79.

66. Lentini R, Martín NY, Forlin M et al. (2017) Two-way chemical communication between artificial and natural cells. ACS Central Science 3(2): 117-123.

67. Cornett EM, Campbell EA, Gulenay G et al. (2012) Molecular logic gates for DNA analysis: detection of rifampin resistance in $M$. tuberculosis DNA. Angewandte Chemie International Edition 51(36): 9075-9077.

68. Kim J and Winfree E (2011) Synthetic in vitro transcriptional oscillators. Molecular Systems Biology 7(465): 1-15.

69. Rondelez Y (2012) Competition for catalytic resources alters biological network dynamics. Physical Review Letters 108(1): 018102.

70. Ulasevich SA, Brezhneva N, Zhukova Y et al. (2016) Switching the stiffness of polyelectrolyte assembly by light to control behavior of supported cells. Macromolecular Bioscience 16(10): 1422-1431.

71. Ulasevich SA, Brezesinski G, Möhwald H et al. (2016) Light-induced water splitting causes high-amplitude oscillation of $\mathrm{pH}$-sensitive layer-by-layer assemblies on $\mathrm{TiO}_{2}$. Angewandte Chemie International Edition 55(42): 13001-13004.

72. Hoshi T, Saiki H and Anzai JI (2003) Amperometric uric acid sensors based on polyelectrolyte multilayer films. Talanta 61(3): 363-368.

73. Ryzhkov NV, Mamchik NA and Skorb EV (2019) Electrochemical triggering of lipid bilayer lift off oscillation at the electrode interface. Journal of the Royal Society Interface 16(150): 20180626.

74. Pennakalathil J, Kim TH, Kim K et al. (2010) Ion-permselective polyelectrolyte multilayer membrane in stalled with a $\mathrm{pH}$-sensitive oxazine switch. Langmuir 26(13): 11349-11354.

75. Andreeva DV, Melnyk I, Baidukova O and Skorb EV (2016) Local $\mathrm{pH}$ gradient initiated by light on $\mathrm{TiO}_{2}$ for light-triggered modulation of polyhistidine-tagged proteins. ChemElectroChem 3(9): 1306-1310.

76. Castañeda AD, Alligrant TM, Loussaert JA and Crooks RM (2015) Electrocatalytic amplification of nanoparticle collisions at electrodes modified with polyelectrolyte multilayer films. Langmuir 31(2): $876-885$.
77. Zahn R, Vörös J and Zambelli T (2014) Tuning the electrochemical swelling of polyelectrolyte multilayers toward nanoactuation. Langmuir 30(40): 12057-12066.

78. Rmaile HH, Farhat TR and Schlenoff JB (2003) pH-gated permeability of variably charged species through polyelectrolyte multilayer membranes. Journal of Physical Chemistry B 107(51): 14401-14406.

79. Gu BX, Xu CX, Zhu GP et al. (2009) Layer-by-layer immobilized horseradish peroxidase on zinc oxide nanorods for biosensing. Journal of Physical Chemistry B 113(18): 6553-6557.

80. Spruijt E, Choi EY and Huck WT (2008) Reversible electrochemical switching of polyelectrolyte brush surface energy using electroactive counterions. Langmuir 24(19): 11253-11260.

81. Liu Y, Yin F, Long Y, Zhang Z and Yao S (2003) Study of the immobilization of alcohol dehydrogenase on Au-colloid modified gold electrode by piezoelectric quartz crystal sensor, cyclic voltammetry, and electrochemical impedance techniques. Journal of Colloid and Interface Science 258(1): 75-81.

82. Mani V, Chikkaveeraiah BV, Patel V, Gutkind JS and Rusling JF (2009) Ultra sensitive immunosensor for cancer biomarker proteins using gold nanoparticle film electrodes and multienzymeparticle amplification. ACS Nano 3(3): 585-594.

83. Zhao J, Bradbury CR and Fermín DJ (2008) Long-range electronic communication between metal nanoparticles and electrode surfaces separated by polyelectrolyte multilayer films. Journal of Physical Chemistry C 112(17): 6832-6841.

84. Cho C, Jeon JW, Lutkenhaus J and Zacharia NS (2013) Electric field induced morphological transitions in polyelectrolyte multilayers. ACS Applied Materials \& Interfaces 5(11): 4930-4936.

85. Onda M, Lvov Y, Ariga K and Kunitake T (1996) Sequential actions of glucose oxidase and peroxidase in molecular films assembled by layer-by-layer alternate adsorption. Biotechnology and Bioengineering 51(2): 163-167.

86. Kelly KD, Fares HM, Shaheen SA and Schlenoff JB (2018) Intrinsic properties of polyelectrolyte multilayer membranes: erasing the memory of the interface. Langmuir 34(13): 3874-3883.

87. Maza E, Tuninetti JS, Politakos N et al. (2015) pH-responsive ion transport in polyelectrolyte multilayers of poly (diallyldimethylammonium chloride) (PDADMAC) and poly(4styrenesulfonic acid-co-maleic acid) (PSS-MA) bearing strong-and weak anionic groups. Physical Chemistry Chemical Physics 17(44): 29935-29948.

88. Chirea M, García-Morales V, Manzanares JA et al. (2005) Electrochemical characterization of polyelectrolyte/gold nanoparticle multilayers self-assembled on gold electrodes. Journal of Physical Chemistry B 109(46): 21808-21817.

89. Lindholm-Sethson B, Gonzalez JC and Puu G (1998) Electron transfer to a gold electrode from cytochrome oxidase in a biomembrane via a polyelectrolyte film. Langmuir 14(23): 6705-6708.

90. Song Y, Wang L, Ren C, Zhu G and Li Z (2006) A novel hydrogen peroxide sensor based on horseradish peroxidase immobilized in DNA films on a gold electrode. Sensors and Actuators B: Chemical 114(2): 1001-1006

91. Thotiyl MO, Basit H, Sánchez JA et al. (2012) Multi layer assemblies of polyelectrolyte-gold nanoparticles for the electrocatalytic oxidation and detection of arsenic (III). Journal of Colloid and Interface Science 383(1): 130-139.

92. Ghostine RA and Schlenoff JB (2011) Ion diffusion coefficients through polyelectrolyte multilayers: temperature and charge dependence. Langmuir 27(13): 8241-8247.

93. Hoshi T, Saiki H, Kuwazawa S et al. (2001) Selective permeation of hydrogen peroxide through polyelectrolyte multilayer films and its use for amperometric biosensors. Analytical Chemistry 73(21): 5310-5315. 
94. Ostendorf A, Cramer C, Decher G and Schönhoff M (2015) Humidity-tunable electronic conductivity of polyelectrolyte multilayers containing gold nanoparticles. Journal of Physical Chemistry C 119(17): 9543-9549.

95. Grieshaber D, Vörös J, Zambelli T et al. (2008) Swelling and contraction of ferrocyanide-containing polyelectrolyte multilayers upon application of an electric potential. Langmuir 24(23): 13668-13676.

96. Wang S, Yu D and Dai L (2011) Polyelectrolyte functionalized carbon nanotubes as efficient metal-free electrocatalysts for oxygen reduction. Journal of the American Chemical Society 133(14): 5182-5185.

97. Sénéchal V, Saadaoui H, Rodriguez-Hernandez J and Drummond C (2017) Electrowetting of weak polyelectrolyte-coated surfaces. Langmuir 33(20): 4996-5005.

98. Jan E, Hendricks JL, Husaini V et al. (2009) Layered carbon nanotube-polyelectrolyte electrodes outperform traditional neural interface materials. Nano Letters 9(12): 4012-4018.

99. Zhou F, Biesheuvel PM, Choi EY et al. (2008) Polyelectrolyte brush amplified electroactuation of microcantilevers. Nano Letters $\mathbf{8}(\mathbf{2})$ : $725-730$

100. Comminges C, Frasca S, Sütterlin M et al. (2014) Surface modification with thermoresponsive polymer brushes for a switchable electrochemical sensor. RSC Advances 4(81): 43092-43097.

101. Dochter A, Garnier T, Pardieu E et al. (2015) Film self-assembly of oppositely charged macromolecules triggered by electrochemistry through a morphogenic approach. Langmuir 31(37): 10208-10214.

102. Aytar BS, Prausnitz MR and Lynn DM (2012) Rapid release of plasmid DNA from surfaces coated with polyelectrolyte multilayers promoted by the application of electrochemical potentials. ACS Applied Materials \& Interfaces 4(5): 2726-2734.

103. Graf N, Tanno A, Dochter A et al. (2012) Electrochemically driven delivery to cells from vesicles embedded in polyelectrolyte multilayers. Soft Matter 8(13): 3641-3648.

104. Chassepot A, Gao L, Nguyen I et al. (2012) Chemically detachable polyelectrolyte multilayer platform for cell sheet engineering. Chemistry of Materials 24(5): 930-937.

105. Gwon K, Kim M and Tae G (2014) A biocompatible method of controlled retrieval of cell-encapsulating microgels from a culture plate. Integrative Biology 6(6): 596-602.

106. Mani V, Chikkaveeraiah BV, Patel V, Gutkind JS and Rusling JF (2009) Ultrasensitive immunosensor for cancer biomarker proteins using gold nanoparticle film electrodes and multienzyme-particle amplification. ACS Nano 3(3): 585-594.

107. Zhu T, Sha Y, Yan J et al. (2018) Metallo-polyelectrolytes as a class of ionic macromolecules for functional materials. Nature Communications 9(1): 4329.

108. Schmidt DJ, Moskowitz JS and Hammond PT (2010) Electrically triggered release of a small molecule drug from a polyelectrolyte multilayer coating. Chemistry of Materials 22(23): 6416-6425.

109. Silva TR and Vieira IC (2016) A biosensor based on gold nanoparticles stabilized in poly(allylamine hydrochloride) and decorated with laccase for determination of dopamine. Analyst 141(1): 216-224.

110. Zahn R, Coullerez G, Vörös J and Zambelli T (2012) Effect of polyelectrolyte inter diffusion on electron transport in redox-active polyelectrolyte multilayers. Journal of Materials Chemistry 22(22): 11073-11078.

111. Si P, Ding S, Yuan J et al. (2011) Hierarchically structure onedimensional $\mathrm{TiO}_{2}$ for protein immobilization, direct electrochemistry, and mediator-free glucose sensing. ACS Nano 5(9): 7617-7626.

112. Feng JJ, Zhao G, Xu JJ and Chen HY (2005) Direct electrochemistry and electrocatalysis of heme proteins immobilized on gold nanoparticles stabilized by chitosan. Analytical Biochemistry 342(2): 280-286
113. Sadman K, Wang Q, Chen SH, Delgado DE and Shull KR (2017) $\mathrm{pH}$-controlled electrochemical deposition of polyelectrolyte complex films. Langmuir 33(8): 1834-1844.

114. Ghosh DS and Leo K (2017) Microcavity-enhanced semitransparent electrodes for oligothiophene small-molecule organic solar cells. Advanced Electronic Materials 3(5): 1600518.

115. Lowman GM, Tokuhisa H, Lutkenhaus JL and Hammond PT (2005) Dye sensitized solar cells incorporating polyelectrolyte multilayer composites. Materials Research Society Symposium Proceedings 836: $1.5 .1-1.5 .6$

116. Skorb EV and Möhwald H (2016) Ultrasonic approach for surface nanostructuring. Ultrasonics Sonochemistry 29: 589-603.

117. Lanchuk YV, Ulasevich SA, Fedotova TA, Kolpashchikov DM and Skorb EV (2018) Towards sustainable diagnostics: replacing unstable $\mathrm{H}_{2} \mathrm{O}_{2}$ by photoactive $\mathrm{TiO}_{2}$ in testing systems for visible and tangible diagnostics affordable by blind people. RCS Advances 8(66): 37735-37739

118. Chen HS, Lin SW, Jiang JM, Su YW and Wei KH (2015) Solutionprocessed zinc oxide/polyethyleneimine nanocomposites as tunable electron transport layers for highly efficient bulk heterojunction polymer solar cells. ACS Applied Materials \& Interfaces 7(11): 6273-6281.

119. Yang D, Fu P, Zhang F et al. (2014) High efficiency inverted polymer solar cells with room-temperature titanium oxide/ polyethylenimine films as electron transport layers. Journal of Materials Chemistry A 2(41): 17281-17285.

120. Zhao XD, Li YQ, Xiang HY et al. (2017) Efficient color-stable inverted white organic light-emitting diodes with outcouplingenhanced $\mathrm{ZnO}$ layer. ACS Applied Materials \& Interfaces 9(3): 2767-2775.

121. Kim HH, Park S, Yi Y et al. (2015) Inverted quantum dot light emitting diodes using polyethylenimine ethoxylated modified $\mathrm{ZnO}$. Scientific Reports 5: 8698 .

122. Rojas HC, Bellani S, Fumagalli F et al. (2016) Polymer-based photocathodes with a solution-processable cuprous iodide anode layer and a polyethyleneimine protective coating. Energy and Environmental Science 9(12): 3710-3723.

123. Jia X, Wu N, Wei J et al. (2016) A low-cost and low-temperature processable zinc oxide:polyethyleneimine ( $\mathrm{ZnO}: \mathrm{PEI}$ ) nanocomposite as cathode buffer layer for organic and perovskite solar. Organic Electronics 38: 150-157.

124. Du X, Lytken O, Killian MS et al. (2017) Overcoming interfacial losses in solution-processed organic multi-junction solar cells. Advanced Energy Materials 7(5): 1601959.

125. Li Z, Zhang X, Liu C et al. (2016) Enhanced electron extraction capability of polymer solar cells via employing electrostatically selfassembled molecule on cathode interfacial layer. ACS Applied Materials \& Interfaces 8(12): 8224-8231.

126. Yan Y, Cai F, Yang L et al. (2017) Versatile device architectures for high performing light-soaking-free inverted polymer solar cells. ACS Applied Materials \& Interfaces 9(38): 32678-32687.

127. Lin Z, Cang J, Zhang J et al. (2014) A work-function tunable polyelectrolyte complex (PEI:PSS) as a cathode interfacial layer for inverted organic solar cells. Journal of Materials Chemistry A 2(21): 7788-7794.

128. Subbiah J, Mitchell VD, Hui NKC, Jones DJ and Wong WWH (2017) A green route to conjugated polyelectrolyte interlayers for highperformance solar cells. Angewandte Chemie International Edition 56(29): 8431-8434.

129. Zhu $X$, Nepomnyashchii $A B$, Roitberg $A E$, Perkinson $B A$ and Schanze KS (2013) Photosensitization of single-crystal $\mathrm{ZnO}$ by a conjugated polyelectrolyte designed to avoid aggregation. Journal of Physical Chemistry Letters 4(19): 3216-3220.

130. Pan Z, Leem G, Cekli S and Schanze KS (2015) Conjugated polyelectrolyte sensitized $\mathrm{TiO}_{2}$ solar cells: chain-length and aggregation 
effects on efficiency. ACS Applied Materials \& Interfaces 7(30): $16601-16608$

131. Sambur JB, Averill CM, Bradley C et al. (2011) Interfacial morphology and photoelectrochemistry of conjugated polyelectrolytes adsorbed on single crystal $\mathrm{TiO}_{2}$. Langmuir 1(27): 11906-11916.

132. Skorb EV and Andreeva DV (2015) Self-healing properties of layerby-layer assembled multilayers. Polymer International 64(6): 713-723.

133. Skorb EV and Andreeva DV (2013) Surface nanoarchitecture for bioapplications: self-regulated intelligent surfaces. Advanced Functional Materials 23(36): 4483-4506.

134. Skorb EV, Möhwald H and Andreeva DV (2017) How can one controllably use of natural $\Delta \mathrm{pH}$ in polyelectrolyte multilayers? Advanced Materials Interfaces 4(1): 1600282.

135. Andreeva DV, Skorb EV and Shchukin DG (2010) Layer-by-layer polyelectrolyte/inhibitor nanostructures for metal corrosion protection. ACS Applied Materials \& Interfaces 2(7): 1954-1962.

136. Andreeva DV, Fix D, Moehwald H and Shchukin DG (2008) Selfhealing anticorrosion coatings based on ph-sensitive polyelectrolyte/ inhibitor sandwichlike nanostructures. Advanced Materials 20(14): 2789-2794.

137. Andreeva DV, Fix D, Moehwald $\mathrm{H}$ and Shchukin DG (2008) Buffering polyelectrolyte multilayers for active corrosion protection. Journal of Materials Chemistry 18(15): 1738-1740.

138. Lamaka SV, Shchukin DG, Andreeva DV et al. (2008) Sol-gel/ polyelectrolyte active corrosion protection system. Advanced Functional Materials 18(20): 3137-3141.

139. Andreeva DV, Sviridov DV, Masic A, Möhwald H and Skorb EV (2012) Nanoengineered metal surface capsules: construction of a metal-protection system. Small 8(6): 820-825.

140. Skorb EV, Baidukova O, Andreeva OA, Cherepanov PV and Andreeva DV (2013) Formation of polypyrrole/metal hybrid interfacial layer with self-regulation functions via ultrasonication. Bioinspired, Biomimetic and Nanobiomaterials 2(3): 123-129.
141. SCAMT (Solution Chemistry of Advanced Materials and Technologies) (2019) https://scamt.ifmo.ru/science/groups/ infochemistry-of-self-organizing-systems/ (accessed 05/03/2019).

142. Yu L, Li J, Wang D et al. (2015) Improved antimicrobial activity and bioactivity of porous $\mathrm{CaP}-\mathrm{TiO}_{2}$ coating through surface nanofunctionalisation. Materials Technology 30(6): B109-B114.

143. Lacasta AM, Cantalapiedra IR, Auguet CE, Penaranda $A$ and Ramırez-Piscina L (1999) Modelling of spatio-temporal patterns in bacterial colonies. Physical Review E: Statistical Physics, Plasmas, Fluids, and Related Interdisciplinary Topics 59(6): 7036-7041.

144. Prindle A, Liu J, Asally M et al. (2015) Ion channels enable electrical communication in bacterial communities. Nature 527(7576): 59-63.

145. Rivera-Chavez F and Bäumler AJ (2015) The pyromaniac inside you: Salmonella metabolism in the host gut. Annual Review of Microbiology 69: 31-48.

146. Gensel J, Borke T, Pazos-Perez N et al. (2012) Cavitation engineered 3D sponge networks and their application in active surface construction. Advanced Materials 24(7): 985-989.

147. Skorb EV, Andreeva DV, Raiski AP et al. (2011) Titanium dioxide for photocatalytic-assisted prophage induction to lytic cycle. Photochemical \& Photobiological Sciences 10: 1974-1978.

148. Bassler BL (1999) How bacteria talk to each other: regulation of gene expression by quorum sensing. Current Opinion in Microbiology 2(6): 582-587.

149. Miller MB and Bassler BL (2001) Quorum sensing in bacteria. Annual Review of Microbiology 55(1): 165-199.

150. Liu J, Prindle A, Humphries J et al. (2015) Metabolic co-dependence gives rise to collective oscillations within biofilms. Nature 523(7562): 550-554.

151. Skorb EV, Antonouskaya LI, Belyasova NA et al. (2008) Antibacterial activity of thin-film photocatalysts based on metal-modified $\mathrm{TiO}_{2}$ and $\mathrm{TiO}_{2}: \mathrm{In}_{2} \mathrm{O}_{3}$ nanocomposite. Applied Catalysis B: Environmental 84(1-2): 94-99.

\section{How can you contribute?}

To discuss this paper, please submit up to 500 words to the journal office at journals@ice.org.uk. Your contribution will be forwarded to the author(s) for a reply and, if considered appropriate by the editor-in-chief, it will be published as a discussion in a future issue of the journal.

ICE Science journals rely entirely on contributions from the field of materials science and engineering. Information about how to submit your paper online is available at www.icevirtuallibrary.com/page/authors, where you will also find detailed author guidelines. 